\title{
Research on Fatigue Damage Evolution of the Base Plate Structure of China Railway Track System III Type Slab Ballastless Track under Heavy Haul Train Load
}

\author{
Zhiping Zeng ${ }^{1}$, Ji Hu ${ }^{1}\left(\mathbb{D}\right.$, Xudong Huang ${ }^{1, *} \mathbb{D}$, Weidong Wang ${ }^{1,2}$, Zhibin Huang ${ }^{1,3}$, \\ Abdulmumin Ahmed Shuaibu ${ }^{1,4}$ (D) Yu Yuan ${ }^{5}$, Zhonglin Xie ${ }^{1}$ and Xianfeng He ${ }^{1}$
}

check for

updates

Citation: Zeng, Z.; Hu, J.; Huang, X.; Wang, W.; Huang, Z.; Shuaibu, A.A.; Yuan, Y.; Xie, Z.; He, X. Research on Fatigue Damage Evolution of the Base Plate Structure of China Railway Track System III Type Slab Ballastless Track under Heavy Haul Train Load. Appl. Sci. 2022, 12, 1694. https:// doi.org/10.3390/app12031694

Received: 9 November 2021

Accepted: 20 January 2022

Published: 7 February 2022

Publisher's Note: MDPI stays neutral with regard to jurisdictional claims in published maps and institutional affiliations.

Copyright: (C) 2022 by the authors. Licensee MDPI, Basel, Switzerland. This article is an open access article distributed under the terms and conditions of the Creative Commons Attribution (CC BY) license (https:// creativecommons.org/licenses/by/ $4.0 /)$.
1 School of Civil Engineering, Central South University, Changsha 410075, China; 203160@csu.edu.cn (Z.Z.); 204811161@csu.edu.cn (J.H.); 204801060@csu.edu.cn (W.W.); 1203160229@csu.edu.cn (Z.H.); abdulshub4u@csu.edu.cn (A.A.S.); 8210202322@csu.edu.cn (Z.X.); walkonrailway@csu.edu.cn (X.H.)

2 MOE Key Laboratory of Engineering Structures of Heavy Haul Railwa, Central South University, Changsha 410075, China

3 Southeast Coastal Railway (Fujian) Co., Ltd., Fuzhou 350001, China

4 Department of Civil Engineering, Faculty of Engineering, Ahmadu Bello University Zaria, Zaria 800242, Kaduna State, Nigeria

5 Information Engineering School, Nanchang University, Nanchang 330031, China; yuyuan@email.ncu.edu.cn * Correspondence: samhuang@csu.edu.cn

\begin{abstract}
To meet the transportation requirements of heavy-haul trains, it is necessary to consider the use of prestressed reinforced concrete ballastless tracks. Therefore, the CRTSIII SBT (China Railway Track System III-type slab ballastless track) has been considered for its convenient construction and geometric adjustment. Considering the problems existing in the base plate of CRTSIII SBT in heavy-haul applications, an indoor test and simulation were conducted to explore the cracking phenomenon of the base plate concrete under fatigue load. The reliability of the simulation was verified through the experimental results. A fatigue crack development law of the base plate structure was established. Furthermore, the influence of the load position, the thickness of self-compacting concrete and axle loads on the fatigue damage of the base plate structure were investigated. For the CRTSIII SBT subjected to heavier axle loads, it is appropriate to thicken the self-compacting concrete layer and strengthen the concrete and steel reinforcement at the plate end to reduce fatigue damage and cracks. The research results can serve as a basis for the optimization of the CRTSIII SBT base plate structure in heavy-haul railway applications.
\end{abstract}

Keywords: China Railway Track System III type slab ballastless track (CRTSIII SBT); base plate structure; large axle load; train load; fatigue performance; numerical simulation; heavy-haul railway

\section{Introduction}

\subsection{Research Background}

1.1.1. Ballastless Track Structure

Japan's Tokaido Shinkansen is the world's first high-speed railway, and is a milestone in the history of high-speed railway construction. After Japan, Germany, Britain, China and other countries have carried out research on the slab ballastless track structure [1-4].

The main structural type of ballastless track used in Japan is a slab ballastless track, which is represented by the Shinkansen slab ballastless track and it is mainly set in tunnel and bridge sections [5]. The common track forms include ordinary A-type ballastless track and frame ballastless track improved on the basis of the A-type ballastless track, as well as a G-type ballastless track for special vibration reduction section and an RA-type ballastless track laid on subgrades [6]. The slab ballastless track in Japan consists of steel rails, fasteners, track plates, a CA mortar adjustment layer, convex abutment and base [7]. In order to meet the requirement for different lines, the slab ballastless track structure has 
different adjustment levels. Changing the type of fastener is the main adjustment, and the convex abutment also plays a vital role [8].

Ballastless track forms in Germany mainly include Rheda, Zublin, Borg, Berlin, ATD and Getrac. The types of track structure are the integral structure and the sleeper-support structure, which are usually laid on the subgrade. The Borg slab ballastless track in Germany is longitudinally connected, which improves the integrity of the track slab structure and increases vertical and horizontal friction [9]. The Rheda type is composed of rails, fasteners, sleepers, concrete slabs and supporting layers. The track slab is cast-in-situ, which is simple for construction. However, the self-weight is large, and the joint surface of new and old concrete is easy to damage [10]. The Zublin structure is also a double-block ballastless track, which has strong overall structure, high connection strength of new and old concrete joint surfaces, high precision of construction mechanization, and good compactness of track bed slab concrete. However, this structure has high requirements for operation and maintenance.

The main representative type of ballastless track in Britain is the PACT type, which has the advantages of low one-time investment, low maintenance costs and large axle load [11]. Later, the elastic support block ballastless track structure was developed in Britain, which has a good vibration reduction effect. Rubber boots are set under and around the sleeper of this structure, and a rubber elastic cushion is settled between the boots. Finally, concrete is poured around and at the bottom of the sleeper.

China's research on ballastless tracks mainly includes three track structures: the slab ballastless track, the double-block ballastless track and the long sleeper embedded ballastless track. The CRTSI slab ballastless track (CRTSI SBT) adopts a unit plate structure based on Japanese ballastless track technology, which is mainly composed of rails, fasteners, track plates, a CA mortar layer, a convex baffle and base; resin material is poured between track plate and convex baffle [5].The CRTSII slab ballastless track (CRTSII SBT) structure is a slab ballastless track developed on the basis of introducing the Borg slab ballastless track, which is composed of steel rails, fasteners, track plates, CA mortar and base plate [9]. The CRTSIII SBT structure was independently developed and designed by China [12]. The main feature is that the limit is realized through boss and groove. These three kinds of slab ballastless tracks have their own advantages and disadvantages. CRTSI SBT has the advantages of clear force transmission and being easy and rapid to repair, but it has obvious weak links, including large fine adjustment workload and poor integrity. The CRTSII has good integrity, controllable cracks and high plate manufacturing accuracy, but its interlayer connection reliability is poor, the plate manufacturing process is complex, maintenance is difficult, durability and service life are unclear, and the cost is high. The CRTSIII has the remarkable characteristics of high safety, convenient maintenance and good stability. It has obvious advantages over the previous two track plates in terms of structural form, durability and maintenance costs. Therefore, the CRTIII slab is one of the ballastless track types with the most development and promotion space in China. During the field investigation of CRTSIII SBT, some problems were found. There were through cracks in the track structure, poor bonding and joint separation between the side of the track slab and the self-compacting concrete. As the track slab may be affected by temperature stress, a complex temperature environment, train load and other factors during use, the internal structure of the track slab changes, and then the external part of the track slab becomes bent and cracked. Finally, the track slab structure is separated from the joint, and even the reinforcement bar is blown out. Therefore, it is necessary to further optimize the design of the CRTSIII SBT.

\subsubsection{CRTSIII SBT Base Plate Structure}

With the development of railway technology around the world, China independently developed the CRTSIII SBT based on existing experience, construction technology and theoretical practice of CRTSI and CRTSII ballastless tracks [13,14]. From top to bottom, the CRTSIII ballastless track (CRTSIII BT) structure consists of rails, elastic fasteners, track 
slabs, self-compacting concrete (SCC), an isolation layer, and base plates as shown in Figure 1 [15]. The rail usually adopted in CRTSIII BT applications is $60 \mathrm{~kg} / \mathrm{m}, \mathrm{U} 71 \mathrm{MnG}$, $100 \mathrm{~m}$ fixed-length non-threaded new rail, while the fasteners are WJ-8B fasteners.

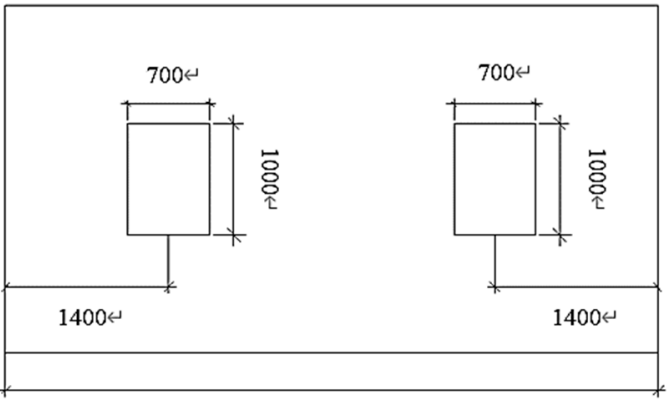

(a)

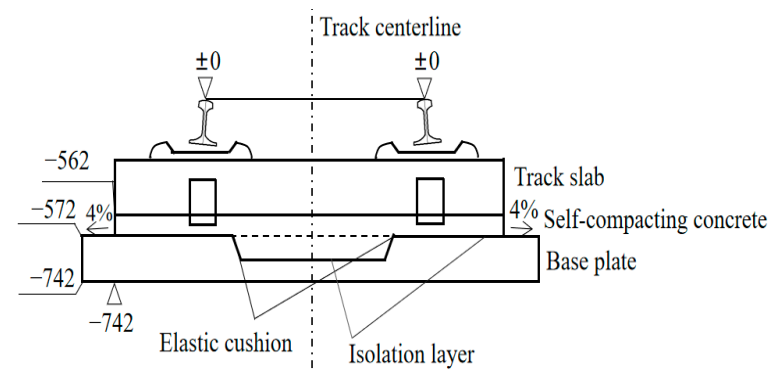

(c)

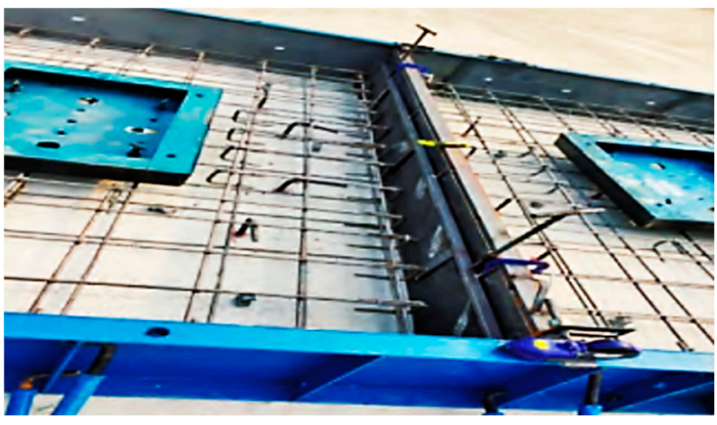

(b)

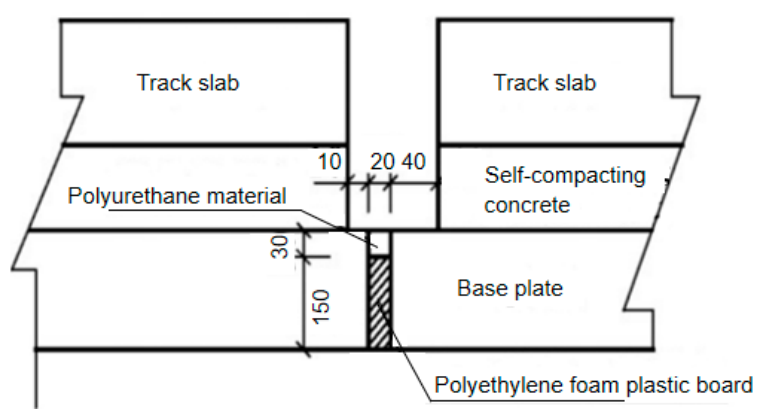

(d)

Figure 1. Schematic and substructure diagram of CRTSIII SBT. (a) Size of base plate; (b) schematic diagram of internal reinforcement; (c) lateral section; (d) longitudinal section.

In this research, the P5600 track slab was selected. The lower section of the SCC is equipped with two bosses and two grooves on the surface of the base plate as well as internal reinforcement mesh for occluding and limiting movement [16] (Figure 1a,b). The isolation layer is made of geotextile materials with a thickness of $4 \mathrm{~mm}$ and has longitudinal and lateral lengths consistent with the SCC. Except for the position where limiting structures are placed, the geotextile materials cover the entire base plate area. In practice, the geotextile materials are laid out to exceed the coverage of the base plate by about $5 \mathrm{~cm}$; however, it is chopped off after the poured SCC layer reaches its standard design strength. The base plate adopts a unit structure, with a C35 concrete strength grade. It is noteworthy that every three-track slab corresponds to a base plate [17]. Expansion joints are provided for every two base plates, with polyethylene foam plastic board as filling material. (Figure 1c,d).

The CRTSIII SBT has been successfully applied to high-speed railways and subway lines; however, currently there is little experience and few studies in the application of CRTSIII to heavy-haul railways. It is, therefore, necessary to carry out research with the view of exploring the characteristics of this track type in service [18]. The CRTSIII SBT base plate is equipped with a limiting groove combined with the upper self-compacting concrete boss to achieve the force transmission and movement limiting functions between the structural layers. This is particularly important and necessary for track stability and maintenance of geometric shape. Experience in the construction and operation of ballastless tracks has revealed that the connection between different structural layers is often weak. Since the base of CRTSIII slab track directly interacts with these basic structures, its fatigue damage performance under train load directly affects driving safety and comfort, especially under large axle loads when damage occurs frequently. At present, the research on CRTSIII 
SBT mostly focuses on the design and construction of each structural layer, and there is scarce research on damage of the base plate.

\subsubsection{Damage Status of the Base Plate of CRTSIII SBT}

At present, many lines in China have adopted CRTSIII SBT. However, China has a large area and complicated geological conditions, leading to many external environmental factors that may result in cracking of the base plate. Currently, cracking is the principal malfunction of CRTSIII SBT base plate. When base plate cracks appear, they can lead to muddying or frost-heave damage, as well as a reduction in the resilience of the base plate concrete and corrosion of the steel bars inside the base plate. To ensure that the durability of the structure is not affected, and the possibility of effectively rectifying the crack that appears in the ballastless track structure, the crack propagation characteristics of the track structure must be understood for prevention and repair of the cracks. Treatment of the problem is particularly critical [19] in meeting the serviceability requirement of the track.

At present, China has laid CRTSIII SBT on many lines, such as the Cheng-Guan line and Beijing-Shenzhen passenger dedicated line [20]. The track structure is in good general service condition, maintenance-free, and has high stability. However, several portions of the base plate revealed some durability issues, primarily in the form of cracks in the grooves of the base plate. Some of the cracks occurred about a week after the base plate was poured during the construction period. Close examination of the track structure revealed that there is the appearance of transverse through cracks at the base plate during the operation stage. The appearance of these cracks not only affects aesthetics but if not controlled, cracks may affect the force/load bearing capacity. Figure 2a shows the cracking problem of the CRTSIII SBT base.

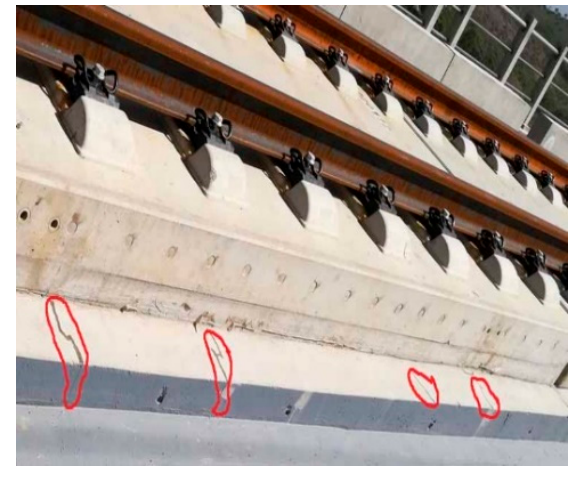

(a)
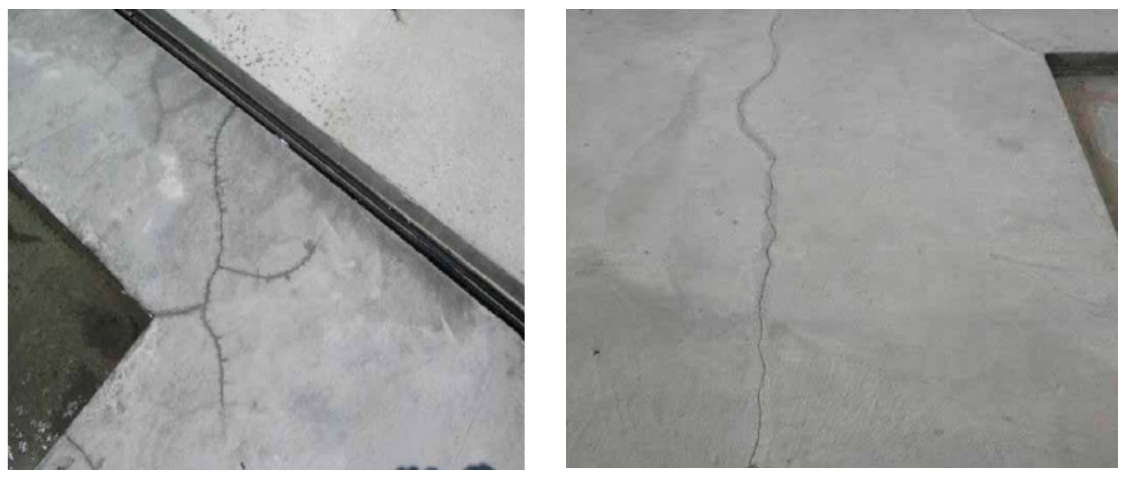

(b)

Figure 2. Cracking problem of CRTSIII SBT base. (a) Overall view of cracking; (b) cracking form 1.

Cracking of the base plate concrete is the principal problem of CRTSIII SBT and occurred frequently. After extensive investigation, it was discovered that the cracks were most concentrated in the groove part and progressed in transverse and lateral directions. As shown in Figure 2b, most of the cracks appeared in the construction stage, particularly between one week to one month after the pouring of the base plate concrete. These cracks have seriously affected the safety and durability of CRTSIII SBT and were also the main cause of other problems of the base plate, such as mud tumbling and frost-heave damage. During operation, it is impossible to visually see whether new cracks have occurred since the groove part of the base plate is completely covered by the upper structure.

Aside from the lateral force of the wheel load the track is subjected to during operations, there are longitudinal forces such as the braking force that impact on the track under many weather conditions. This loading condition has a long-term effect when cyclically acted on the track structure and accumulates over time. The cracks might buckle, and expand and, consequently, penetrate one another, leading to the emergence of lateral and lateral 
through cracks. The emergence of cracks in the ballastless track allows other track problems to occur.

For heavy-haul railways, the track structure is prone to fatigue damage owing to the lengthy impact of large train loads and the external temperature and humidity environment. In recent years, much research has been done on structural damage detection methods and detection principles.

In [21], Min-Shui Huang, based on a genetic algorithm, proposed a vibration-based damage identification method, which is used to identify the location and severity of structural damage under temperature change and noise. A new damage identification optimization algorithm is proposed in [22], called bare bones particle swarm optimization with double jump (BBPSODJ), which has good adaptability. In [23], a method combining an autoregressive (AR) time series model and two-step artificial neural networks (ANNs) is proposed to identify damage under temperature change. In [24], Chengbin Chen proposed a hybrid algorithm for damage detection of complex structures; the ant colony optimization algorithm is combined with the improved Nelder Mead algorithm. In [25], Chengbin Chen combined a weighting strategy with tracking minimum absolute contraction and selection operator (lasso) to form a new structural damage detection method. Zhenpeng Wang [26] obtained the functional relationship between temperature and frequency through experiments, established a model between them, and identified structural damage under the influence of temperature according to the particle swarm optimization (PSO) algorithm. Chu-Dong Pan [27] proposed a new moving average Tikhonov regularization method, which can accurately identify motion force and can be used for structural damage prevention and control. Zepeng Chen [28] proposed a new damage index (CMS) to obtain a sparse representation of the acceleration response for damage identification, so as to extract damage sensitive features from the measured acceleration response.

At present, these structural damage detection methods have been extensively applied in civil engineering, but their application in structural damage identification of CRTSIII BT on heavy-haul railways is relatively limited. To promote the application of structural problem detection methods in this regard, to prevent, reduce and timely control structural fatigue damage, study of the fatigue damage performance of CRTSIII BT structure on heavy-haul railway is required, which has important engineering value.

\subsubsection{Study on Fatigue Analysis of Slab-Type Track Structure}

Under fatigue loading, the prestressed steel rod of the track slab often fractures. In addition, a common problem of channeling occurs in the applications of CRTSI and III slab ballastless tracks. During the fabrication, transportation, and installation of the track slab, the track slab is subjected to external forces that make the corners or edges break and cause the appearance of small cracks along the lower border of a conventional base plate frame. Some of the cracks, after initiation, can progress into various areas of the base plate. Consequently, the cracks cause the base plate to eventually fracture, thereby impacting on the safety and service life of trains [29].

Due to the shrinkage and creep of the ballastless track, the vibration caused by the train's dynamic load, the sudden drop in the external environment temperature, and the uneven distribution of the water-cement ratio of the track slab, corrosion of the steel bar and the carbonization of the concrete occur in service. This has an impact on the durability of the structure. Due to the fact that the track slab is prefabricated with reinforced concrete with different tensile and compression properties, under the effect of overall cooling or negative temperature gradient, the track slab is prone to micro-cracks [30]. After the appearance of these cracks on the track slab, long-term exposure to the forces of weathering in the environment cause the concrete to peel off. The infiltration of rainwater into the cracks also significantly increase the stress level at the crack tip, which accelerates the deterioration of the base plate, which negatively impacts on the service life and performance of the base plate. 
The concept of fatigue damage can be understood as the material's performance attenuation under the action of load cycles. Regarding the damage and destruction of the track slab, Tarifa [31] carried out research on the Shinkansen slab track structure. First, concrete cubes were used as the test piece to carry out a compression fatigue test to determine the required parameters of the fatigue model, and then three-point bending fatigue was performed. In the experiment, a sinusoidal cyclic force was loaded on the prestressed concrete slab. The stiffness change and the evolution of the slab section displacement before and after fatigue were obtained. The initiation process of the track slab cracking failure was also analyzed. Takahashi and Sekine [32] conducted an experimental study on track slab materials taking the freeze-thaw damage and deterioration of track slabs into account. They also considered the sunshine exposure and the chemical reaction of the track slab material. French scholar Chapeleau [33] conducted a structural fatigue experiment on the track slab structure and used sensors to monitor crack development and propagation inside the slab. Zhao Pingrui et al. [34] took into account factors such as concrete strength, reinforcement ratio and steel bar diameter, and used a universal testing machine to stretch the concrete members to simulate the crack development process of the track bed slab in order to test the stress distribution during structural cracking. Lin Hongsong et al. [35] established a finite element model of a ballastless track with cracks based on the linear elastic fracture theory to analyze the effect of cracks in the base plate under train load. Zeng established a finite element model of a heavy-haul train and obtained the mechanical characteristics of track structure under different load conditions [36]. Zeng also established the CRTSI ballastless track structure by using the finite element method and studied the displacement and acceleration of the structure under different working conditions [5].

It can be deduced from the foregoing that there are extensive studies on the spatial mechanical characteristics of CRTSIII SBT. However, the studies mainly underline the base stress state under dynamic load of the subway and EMU (Electric Multiple Units) trains and do not consider the structure of the base plate under heavy train loading.

In addition, most of the research on the damage characteristics of the base plate uses the linear elastic model [37]. Thus, this study seeks to probe fatigue damage and dynamic characteristics of the CRTSIII BT base plate under a heavy-haul load. In order to accurately reflect the tension and compression anomalies as well as the damage characteristics of the base plate, a finite element-based CRTSIII track model under heavy-haul train (HHT) loading was established to monitor fatigue evolution of base plate under fatigue load. The damage characteristics of the base plate under the fatigue load of an HHT was studied, and consequently the damage evolution law of the base plate under HHT load, different loading points and self-compacting concrete layer thickness on the fatigue characteristics of the base plate were further studied.

Yu Zhiwu [12] conducted indoor tests on a CRTSIII SBT structure, established the corresponding simulation calculation model based on ANSYS, analyzed the mechanical characteristics of the CRTSIII SBT, and obtained its damage law under a high-speed train load. Zeng Zhi-ping [18] carried out an experimental study on a full-scale model of a CRTSIII slab track structure, applied 30 million cyclic loads to the structure, and analyzed the evolutions of dynamic and static stiffness and acceleration of each layer structure after fatigue load. Xu Qingyuan [38] established a spatial dynamic model of vehicle CRTSIII slab track subgrade and studied the influence of the vehicle number on the characteristics of vehicle-track-subgrade system. Based on the self-developed preloading device, Kunlin Ma [39] studied the performance evolution and damage of SCC subjected to load together with freeze-thaw cycle.

\subsection{Research Content}

\subsubsection{Necessity of this Research}

Nowadays, heavy-haul lines in China and overseas are still dominated by ballasted track structures [40]. With the increase of axle loads and the volume of traffic operating on these lines, the shortcomings of the ballasted track structure have become prominent. On 
the one hand, the large axle load and large capacity of HHTs impacts negatively on the track structure causing damage. The frequency of damage to track components such as rails, welded joints, and fastener backing plates has increased significantly, and pulverization and compaction of the ballast bed has led to failure in the form deformation that further intensify the dynamic interaction between the wheel and rail. Because of the cyclical action of the HHT load, track maintenance and repair works become more difficult, while the increase in axle load and transportation volume of heavy-haul railways has greatly increased the track maintenance workload, and the busy transportation tasks have reduced the effective line maintenance time. Some problems cannot be rectified in time, and this further aggravates damage to the track structure. In long tunnels, where there is serious space constraint, there is limitation of tunnel clearance height and cross-sectional area, which hinders the entrance of large maintenance machinery, thus making the maintenance of track structure within the tunnel section harder. Therefore, the structural defects of ballasted tracks restrict the development of heavy-haul railways to a certain extent.

In recent years, the use of ballastless tracks has increasingly become a popular option on high-speed railways, mixed passenger and freight transportation lines and urban rail transit lines due to their qualities of excellent ride comfort, high stability, low maintenance and good durability. Based on the consideration of the problems earlier highlighted on the application of heavy-haul railway ballastless tracks, researching the applicability of ballastless track structures for heavy-haul railway applications is required.

The CRTSIII slab has structural stability and good integrity, and it has no obvious weakness. It also has the characteristics of a simple structure, high manufacturing accuracy, fewer surface cracks or no cracks, and small fine adjustment workload. Therefore, this kind of slab is widely used in railways. A great number of tests and theoretical studies have been done at home and abroad on the mechanical properties of heavy-haul railways, CRTSIII SBT and ballastless tracks of heavy haul railways. However, looking at the research results, there are few reports on the theoretical and test studies on the structural mechanical properties of CRTSIII SBT under the action of HHT, especially for the base plate structure. Study of the fatigue damage evolution of the base plate structure under the load of the large axle load will not only enable the smooth implementation of this type of track for heavy-haul application, but also enable the strengthening and optimization of the track structure form [41].

\subsubsection{Research Objectives}

Since CRTSIII SBT is typically applied for low-axle load railways, it has apparent advantages such as rational structure, lower price, and less maintenance work. Thus, this paper pays attention to the optimization of CRTSIII SBT to make it meet the requirements of heavy-haul railways with large-axle loads. The objectives are as follows.

(1) Based on experiments and finite element research, explore the stress of the base plate of CRTSIII SBT withstanding heavy train force to judge whether it is available for heavy-haul railways.

(2) Through comparing the indexes of CRTSIII SBT under different fatigue loads, verify whether CRTSIII SBT has a good ability to withstand larger loads after the damage of fatigue load.

(3) Larger load improvements are made to CRTSIII SBT to make sure that it can meet the situation of larger axle load trains that may be operated and serve as an important reference for structural member selection and design of heavy-haul railway track $s$ under large axle loads.

\subsubsection{Research Methods}

In the light of international study methods of ballastless track structures, the following methods were adopted to search the mechanical properties of CRTSIII SBT and verify whether it can be utilized by heavy-haul railways. 
(1) Based on the results of our previous study on the fatigue behavior of the selfcompacting concrete of CRTSIII SBT under heavy haul train loads, finite element simulation was used to check the validity of the base plate structure model by carrying out relevant experiments.

(2) Based on the verified base plate model to study the crack development law and damage mode of the base plate, the position of the load, and the impact of the axle load on the base plate under the fatigue load of the HHT was explored.

(3) The influence of structural fatigue damage of base plate was analyzed, and e changes in the mechanical properties of the base plate structure under different working conditions were obtained as they apply to the operations of the CTRSIII slab and slab ballastless tracks in heavy-haul railways.

For convenience, a table of nomenclature to include all acronyms, symbols and variables is provided at the end of Section 1.2.3, as seen as Table 1.

Table 1. Abbreviations, Symbols and Variables.

\begin{tabular}{ccc}
\hline & Abbreviation/Symbol/Variable & Full Name/Meaning \\
\hline & CRTSI SBT & China Railway Track System I-type slab ballastless track \\
CRTSI SBT & China Railway Track System II-type slab ballastless track \\
CRTSIII SBT & China Railway Track System III-type slab ballastless track \\
CRTSIII BT & CRTSIII ballastless track \\
CRTSIII & China Railway Track System III-type \\
Abbreviations & HHT & Hehaul train \\
& SCC & Self-compacting concrete \\
EMU & Electric Multiple Units \\
& WJ-8B fasteners & Non-separable fastener with iron base plate (iron base plate of type B) \\
\hline Dymbols and & D & structural damage \\
variables & $\mathrm{N}_{f}$ & Number of load actions \\
& $\Delta \varepsilon_{r}$ & Number of ultimate fatigue loads \\
& $\varepsilon_{0}$ & Internal fatigue residual strain \\
& $\sigma_{\mathrm{s}}$ & Ultimate strain \\
& $f_{y}$ & Stress of steel bar \\
$f_{c}$ & Initial yield strength of reinforcement \\
& & Design value of concrete axial compressive strength \\
\hline
\end{tabular}

\section{Indoor Experiment and Establishment of Finite Element Model}

\subsection{Indoor Test Model}

To figure out how the CRTSIII SBT behaves subjected to fatigue loading, our team carried out related experiments earlier and achieved remarkable results [42]. Therefore, based on the conclusions of the existing base plate fatigue test, the established model of fatigue-loaded CRTSIII SBT base plate was verified, and then used for subsequent studies. The process and details of the experiment in detail, are as follows.

The relevant information obtained in the study through the tests were:

- Strain: mainly the lateral and longitudinal strain of the base concrete.

- Displacement: including the relative displacement of the rail and track slab.

- Acceleration: the acceleration of the base.

The test components mainly included sheet strain gauges, needle strain gauges, displacement sensors, acceleration sensors, etc. Some of the test components are shown in Figure 3.

The acceleration, displacement, and strain in this experiment were all collected by a data acquisition system, which saved the data in the computer in real-time, thereby making it easy to process further.

(1) Stress-strain test

(i) Test content The lateral and longitudinal strain of the base concrete. 


\section{(ii) Test program}

Vibrating wire needle strain gauges, embedded sheet strain gauges, and waterproof sheet strain gauges were applied to measure the lateral and longitudinal strain of concrete. The strain gauges were placed on the surface of the track slab, pre-embedded in the SCC and the inside of the base. Based on the numerical calculations, three characteristic sections were along the longitudinal direction of slab, right below the loading point and the end of slab. Combined with the design of the reinforcement of each structural layer, the layout of each test element is shown in Figure 4. In Figure 4, "q", " $\mathrm{f}$ ", " $\mathrm{h}$ ", , $\mathrm{s}$ ", " 1 ", " $\mathrm{t}$ ", respectively, represent longitudinal quarter, longitudinal three quarters, longitudinal plate middle lateral plate middle, lateral plate edge, longitudinal, and lateral; for example, " $\mathrm{q}-\mathrm{h}-\mathrm{t}$ " represents the longitudinal quarter of the slab transverse strain in a transverse slab. In Figure $4 c$, the upper and lower concrete needle strain gauges of the base are respectively $50 \mathrm{~mm}$ away from the upper and lower surfaces of the base.

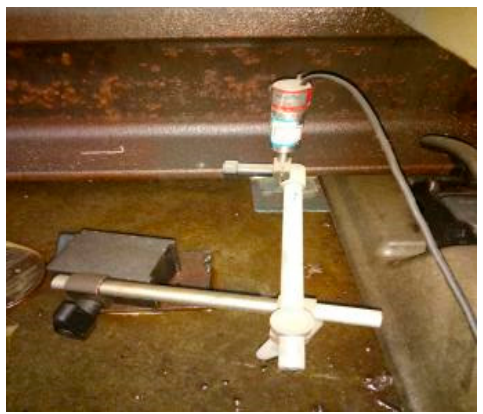

(a)

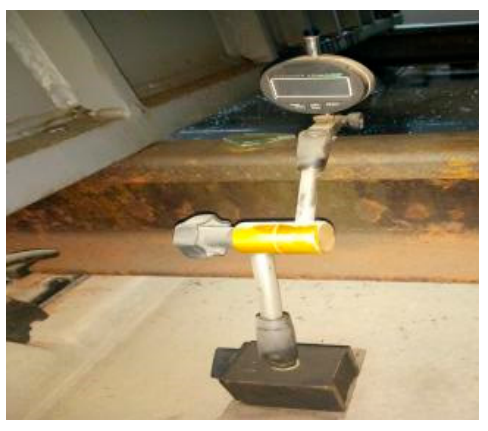

(b)

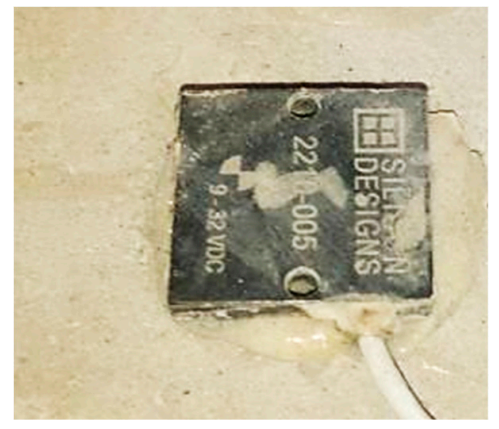

(c)

Figure 3. Figures of typical test components installed for use. (a) Dynamic displacement meter; (b) dial indicator; (c) accelerometer.

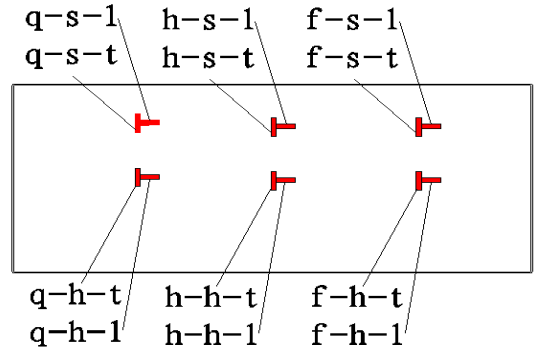

(a)

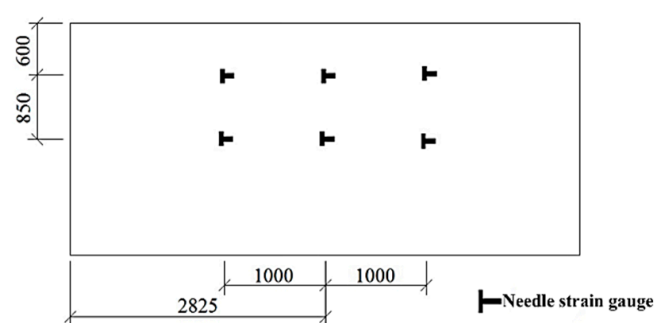

(b)

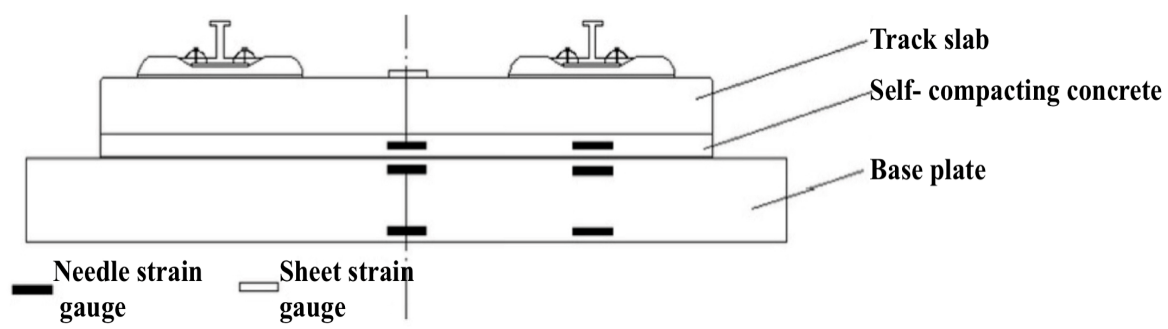

(c)

Figure 4. Layout of strain gauges. (a) Schematic diagram of corresponding symbols; (b) layout drawing of needle strain gauge; (c) cross-sectional view of strain gauge layout. In (a), "q", " $\mathrm{f}$ ", " $\mathrm{h}$ ", " $s$ ", " 1 ", " $\mathrm{t}$ ", respectively, represent longitudinal quarter, longitudinal three quarters, longitudinal plate middle lateral plate middle, lateral plate edge, longitudinal, and lateral. 
(2) Displacement and acceleration test

(i) Test content The test content includes the relative displacement of rail and slab, track slab and base, and the acceleration of track slab and base plate.

(ii) Test program

The test plan specifies the use of a dynamic displacement sensor and an acceleration sensor. The No. 20 sensor, which is utilized to measure displacement and acceleration changes, is positioned at the edge of base under load (Figure 5).

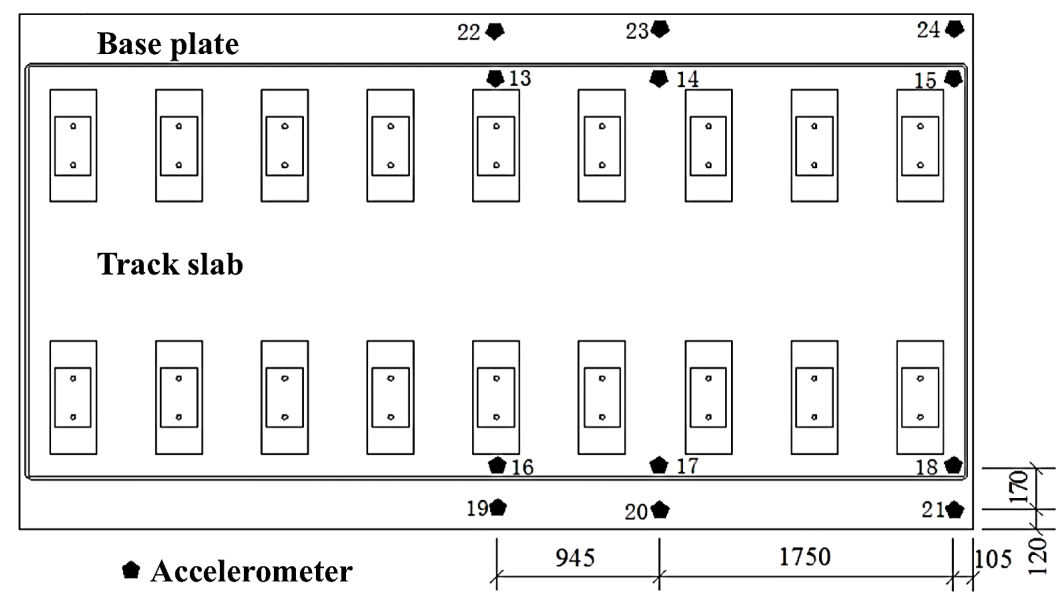

Figure 5. Sensor floor plan.

\section{(3) Production of the test model}

The slab was manufactured in a track slab factory following the standard process criteria. The SCC layer, base and rigid supporting foundation were built in the light of the design drawings and construction process specifications. During the building phase, the rails and fasteners were installed, together with the corresponding test components (Figure 6) [41].

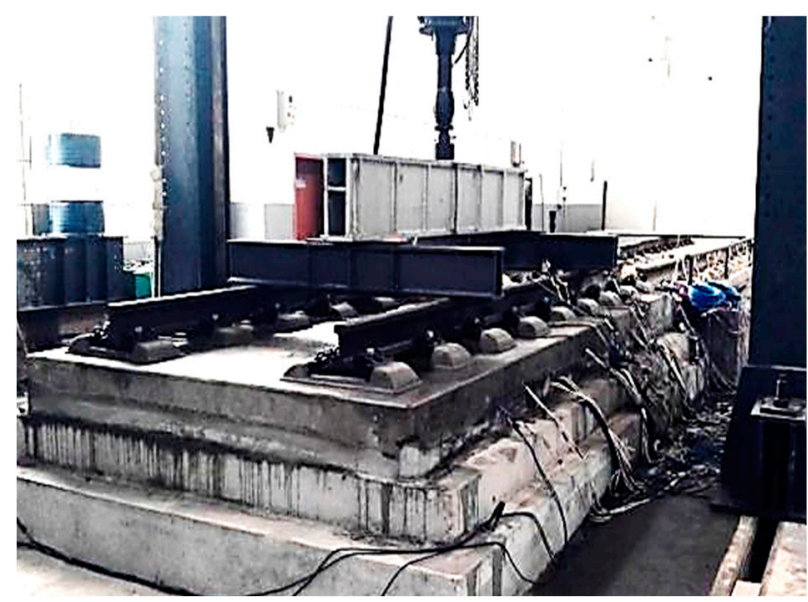

Figure 6. Loading device.

In this test, a simplified calculation method is used to obtain the simulated dynamic load. According to the development trend of heavy haul railway, the maximum axle load is calculated as $30 \mathrm{t}$, the vertical fatigue live load is taken as 1.5 times of the static wheel load, the upper limit value of design fatigue load is taken as $90 t$, and the lower limit value of fatigue load is taken as $9 \mathrm{t}$, according to the rule that lower limit value $\div$ upper limit value $=0.1$ [43]. The static loading test is carried out in stages of $50 \mathrm{kN}, 100 \mathrm{kN}$ and until to $900 \mathrm{kN}$. 
The simulated fatigue load method of the experiment, adopted is based on survey data and theoretical analysis, coupled with on-site measurements. In order to obtain the load effect-time history curve of each loading event under the simulated fatigue load of the check section during the service period, first, an appropriate simulated fatigue train or a series of fatigue trains was created, and then computer simulations were used to obtain the load effect-time history curve of each loading event under the simulated fatigue load. Furthermore, the cycle counting method to determine the load effect spectrum of each loading event was used. The equivalence constant-amplitude repeated load in the fatigue test was obtained the load effect spectrum and the fatigue damage equivalence.

\subsection{Finite Element Model}

\subsubsection{Model Parameter Settings}

The components of CRTSIII SBT structure system mainly include steel rails, slabs, SCC layers, base plates and offline supporting foundations. The fatigue-loaded model of the CRTSIII SBT structure system in the three tunnels was built by the finite element calculation software ANSYS. The slab gap was set between two adjacent slabs, with a width of $0.07 \mathrm{~m}$. For mitigating the effect of the boundary, the track structure at the middle position was monitored. The basic parameters of each structure are shown in Table 2.

Table 2. Main structure parameters.

\begin{tabular}{cccccc}
\hline & Rail & Slab & Self-Compacting Layer & Base & Offline Basis \\
\hline Elastic Modulus (MPa) & 210,000 & 36,000 & 34,000 & 32,000 & - \\
Poisson's ratio & 0.3 & 0.2 & 0.2 & 0.2 & - \\
Stiffness $(\mathrm{MPa} / \mathrm{m})$ & - & - & - & 2500 & 1200 \\
Density $\left(\mathrm{kg} / \mathrm{m}^{3}\right)$ & 7800 & 2500 & 2500 & - \\
\hline
\end{tabular}

To realize the mechanical properties of different track structures, the rail was simulated by beam 188 element, the track plate, SCC and base plate were simulated by solid element solid65, and the offline foundation was simulated by spring element combin14. The track slab and the SCC layer were consolidated, and the contact relationship between the SCC and the base slab was simulated by target170 element.

Figure 7 shows the lateral and longitudinal diagrams of the structure [41]. Table 3 shows the simulation element adopted by each structure.

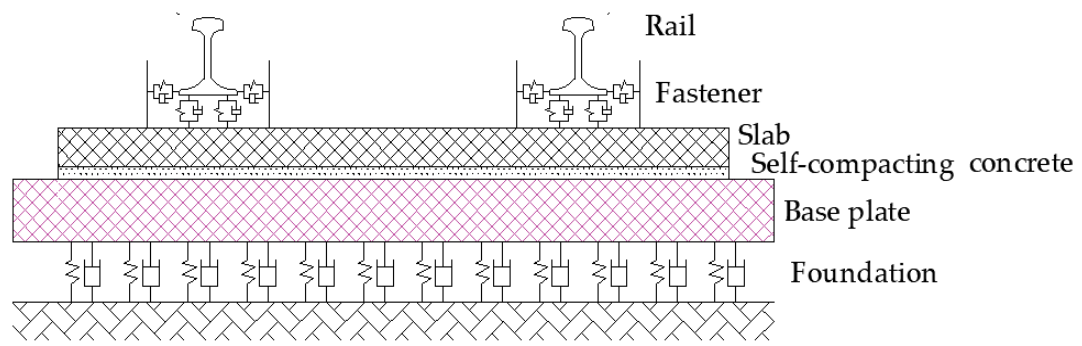

(a)

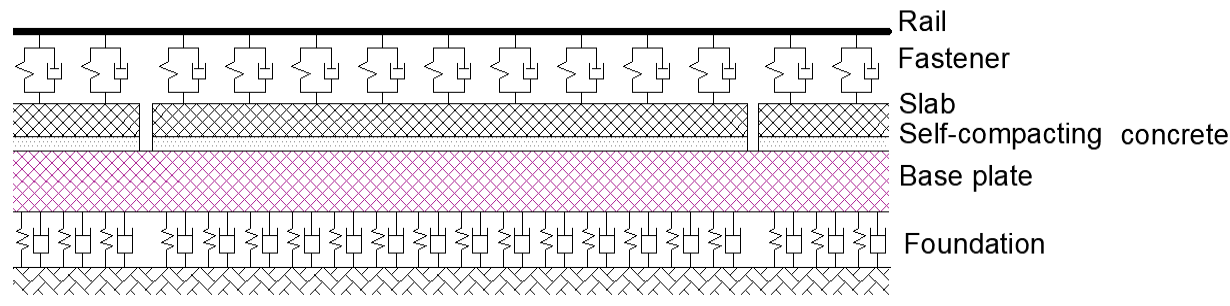

(b)

Figure 7. The CRTSIII SBT structure system. (a) Lateral structure; (b) longitudinal structure. 
Table 3. Finite element for each structure.

\begin{tabular}{cc}
\hline Structure Part & Model the Selected Element \\
\hline Concrete & Solid65 element \\
Rail & Beam188 element \\
Fasteners $/$ foundation & Combin14 element \\
The base plate is in contact with the self-compacting concrete layer & Contact174, target170 element \\
Track slab in contact with self-compacting concrete & Contact174, target170 element \\
\hline
\end{tabular}

\subsubsection{Criteria for Fatigue Failure of Slab Ballastless Track Structure}

When analyzing the fatigue load of the track slab, it is necessary to simplify the fatigue shape according to the fatigue characteristics of the steel and concrete materials (Figure 8) to obtain the fatigue analysis of unequal step length in the numerical simulation, where $\mathrm{D}$ represents structural damage, $N$ represents the number of load actions, and $N_{f}$ represents the number of ultimate fatigue loads [41].

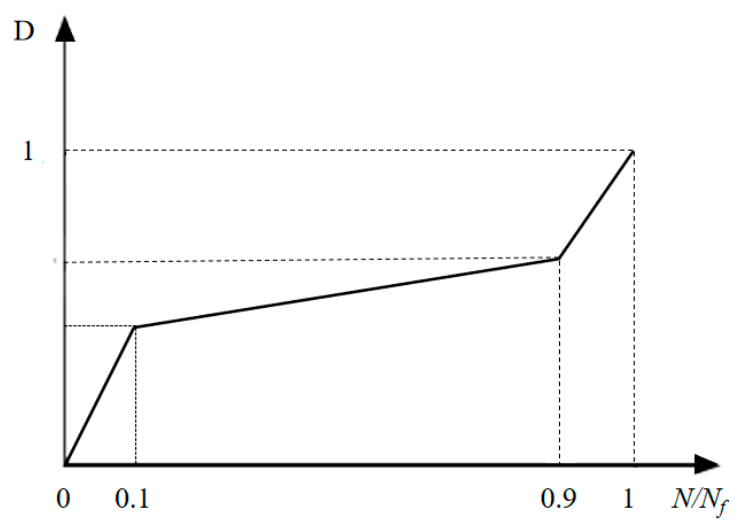

Figure 8. Three-stage simplified diagram of track slab under fatigue load.

(1) The initial stage of fatigue. In the process of initial fatigue, track damage caused by fatigue gradually begins to occur. Therefore, a smaller fatigue step should be used in the simulation at this stage, and the fatigue step lengths adjacent to this stage can be different.

(2) The development stage of fatigue. This process is the main stage of fatigue damage to the track slab, accounting for about $80 \%$ of the total fatigue time [41]. At this stage, the damage of the slab presents a stable development trend. Therefore, in the numerical simulation, the simulation can be carried out with an equal step length. The step length can also be longer than the initial stage of fatigue, and the fatigue load can be applied in the form of a cyclic jump.

(3) The failure stage of fatigue. At this stage, micro-cracks have been generated inside the track slab due to long-lasting fatigue, so the fatigue damage develops rapidly and maintains an unstable trend. Therefore, in the numerical simulation at this stage, the fatigue step length should also be relatively small.

According to the description of the three stages of fatigue failure of the track slab, the three stages in the entire fatigue process can each account for 10,80, and 10\%, respectively of fatigue failure. Therefore, using an interpolation method, the fatigue characteristics of the track slab under the action of adjacent load steps can be related to each other. Thus, a whole process analysis model of the track slab under the cumulative action of fatigue load can be established, which greatly simplifies the fatigue numerical simulation of the track slab. [29].

(1) Criteria for failure judgment of track slab concrete

Through the continuous action of the fatigue load, the internal damage of the track slab concrete structure continues to spread. Therefore, after a large number of cycles of 
fatigue load, the mechanical properties of its structure are destroyed because the maximum stress necessary to cause cracking of the track slab concrete has not been reached [44].

According to the long-term study on the fatigue performance of track slab concrete, it can be deduced that the internal fatigue residual strain $\Delta \varepsilon_{r}$ of the track slab concrete structure under the same amplitude of long-term load is $40 \%$ of the ultimate strain $\varepsilon_{0}$. At this threshold value, the concrete structure of the track slab has already suffered serious internal damage and cannot continue its service as designed. Thus, the concrete structure of the track slab is said to have failed. The damage criteria are expressed in Equation (1) below:

$$
\Delta \varepsilon_{r} \geq 0.4 \varepsilon_{0}=0.4 f_{c} / E_{0}
$$

\section{(2) Criteria for failure judgment of rail slab reinforcement}

Because the rail slab is equipped with a steel structure, the steel undergoes brittle fracture under repeated fatigue loads. Consequently, the fatigue failure criterion can be indicated by the critical value of brittle failure. Therefore, the stress $\sigma_{s}$ of the steel bar is chosen as its yield strength as the basic for failure:

$$
\sigma_{s} \geq f_{y}
$$

\subsubsection{Analysis of the Whole Process of Fatigue Damage of Track Slab}

Based on the above criteria for fatigue failure of steel and concrete structures inside the track slab, a basic analysis flow chart of the fatigue failure of the track slab system under repeated loads of heavy-haul trains is shown in Figure 9.

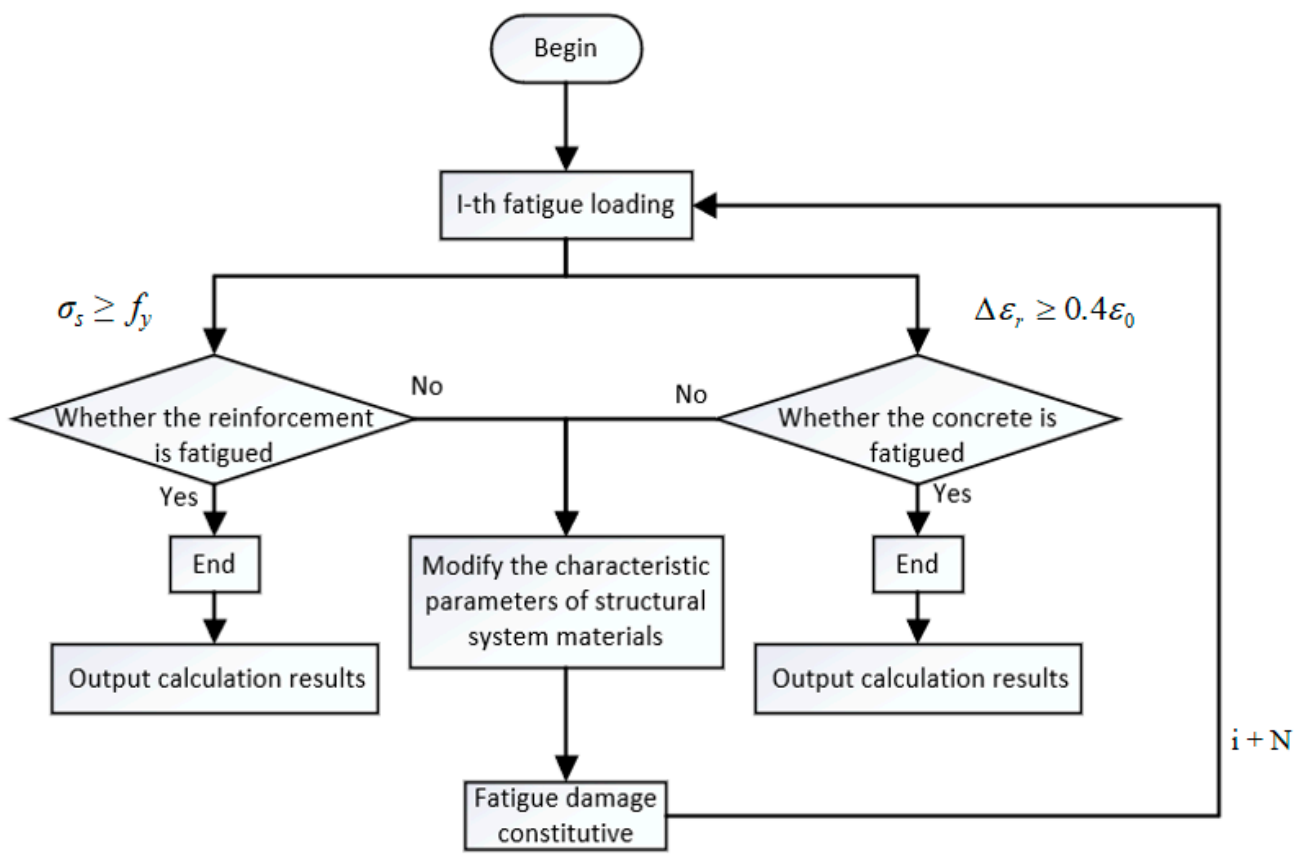

Figure 9. Whole process analysis diagram of fatigue damage of CRTSIII BT structure system.

(1) Equal-amplitude fatigue load loading method. Due to the preliminary simplification in the application of the fatigue load of the heavy-haul train in this model, it is necessary to consider the period of fatigue times. That is, when the fatigue load action time is $\mathrm{N}$, it is necessary to comprehensively consider the damage of the steel and concrete structure after the previous fatigue load. At the same time, it is expected that the remaining strength after the fatigue load will gradually increase with the residual strain of the fatigue load and then simulate the calculation of the $\mathrm{N}_{\text {th }}$ fatigue load.

(2) For the fatigue analysis of the track slab after a certain fatigue load loading simulation, it is necessary to determine whether the track slab structure will undergo deep 
structural damage, i.e., considering the actual fatigue failure judgment criteria of the track slab concrete and steel reinforcement. When the overall structure of the track slab is fatigued, the fatigue cycle loading should end immediately. If the track slab structure has not been fundamentally damaged, the above loading method can continue until the track slab is fatigued. Consequently, the performance parameters of the steel and concrete structure of the track slab are updated in real-time, and the process is returned to step (1) to continue its mechanical analysis.

(3) Repeat step (1) and step (2) until fatigue failure occurs to the structure.

\subsection{Finite Element Model Verification}

\subsubsection{Model Verification under Initial Static Force}

According to the loading method of fatigue test of CRTSIII SBT structure system mentioned in previous studies, a two-axle four-wheel loading on the steel rail was adopted, as shown in Figure 10 [41]. According to the graded loading method adopted in the experiment, the load in the numerical simulation was divided into five grades as follows: 200, 400, 600, 800 and $900 \mathrm{kN}$. Figure 11 compares the calculated value of the structural stress of every layer with the test value. After calculations, for the measuring point right below the loading point, the longitudinal and lateral stress errors between the calculation and measured value of the concrete on upper surface of track slab reach the peak at $18.2 \%$ and $20.0 \%$, respectively, and that of SCC layer are $19.2 \%$ and $20.0 \%$, respectively. The errors at the upper concrete of the base are $16.1 \%$, and $18.6 \%$, respectively.

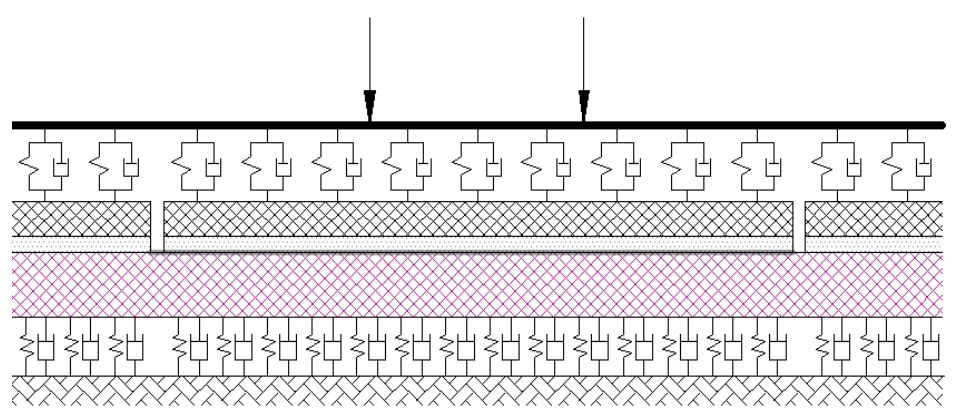

Rail

Fastener

Slab

Self-compacting concret

Base plate

Foundation

Figure 10. Load loading method.

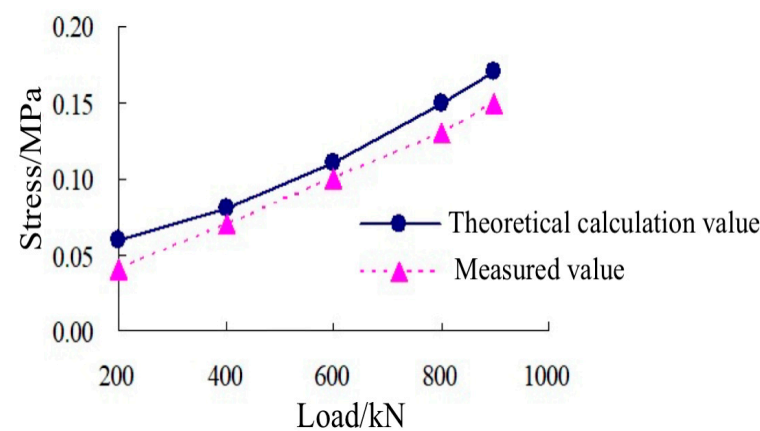

(a)

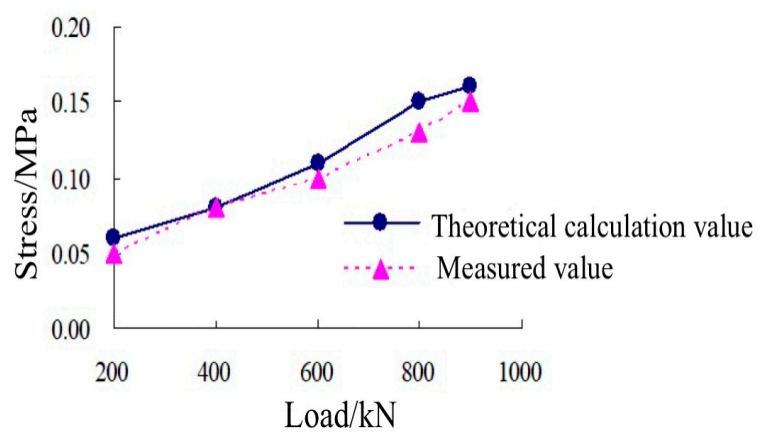

(b)

Figure 11. Diagram of stress of the upper concrete of the base plate. (a) Longitudinal stress; (b) lateral stress.

\subsubsection{Model Verification under Fatigue Loading}

According to the results of static loading, the established finite element model under fatigue load was verified to see whether it matched with the experimental data.

The relative displacement of rail to track slab (Figure 12a), and the base concrete stress (Figure 12b) were verified after a fatigue load of 2, 4, 6, and 8 million times. 


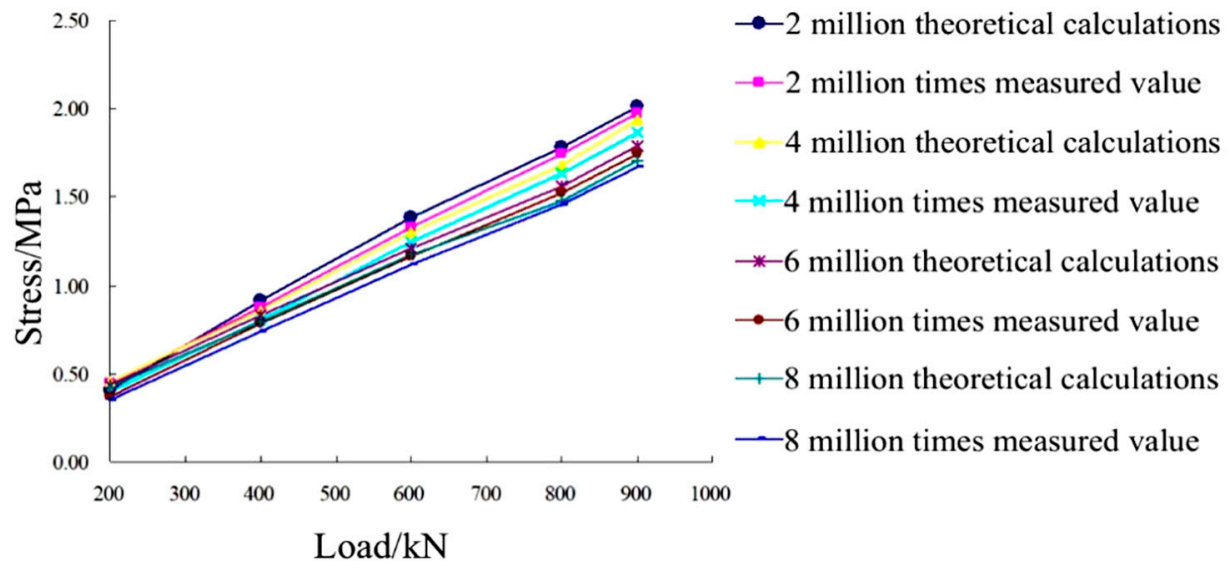

(a)

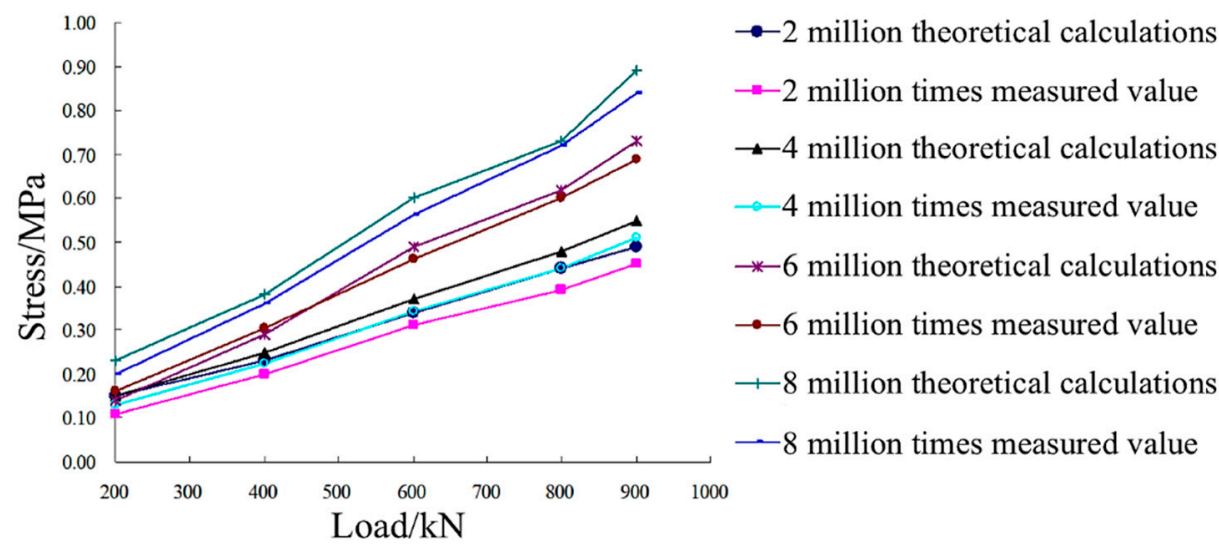

(b)

Figure 12. Variation characteristics of structural force and displacement after fatigue loading. (a) The vertical displacement of the rail just under the loading point relative to the track slab; (b) longitudinal stress of the concrete base just below the loading point.

After 2 million fatigue loads, the vertical displacement of the rail directly below the loading point relative to the track slab had a maximum error between the calculation and measurement with $6.8 \%$. As the fatigue load increased to 4 million times, the error was $12.5 \%$, reaching a maximum. At a fatigue loading application of 6 and 8 million times, the maximum error increased to $16.2 \%$ and $20.0 \%$, respectively.

With regards to the longitudinal stress of the upper concrete layer of the base plate just below the loading point (Figure 12b), when the fatigue force was loaded for 2 million times, the maximum error between the two situations was $17.2 \%$, for 4 million times the maximum error was reduced to $15.4 \%$, and for 6 and 8 million times, the maximum error was $12.5 \%$, and $15.0 \%$, respectively.

By comparing the results, the fatigue-loaded numerical model analyzed the mechanical behavior of CRTSIII SBT system under HHT force very well.

\section{Analysis of Fatigue Damage Law of Base Plate Structure}

\subsection{Analysis of Force Characteristics of Base Plate Structure System}

To monitor the fatigue damage analysis of the CRTSIII SBT structure system under the action of a heavy-haul train, the force distribution characteristics of the structural system were analyzed first. In the light of a heavy load developing trend and "Code for Design of Heavy Haul Railway", the static wheel load was taken as $150 \mathrm{kN}$ [44]. The fatigue load was taken as 1.5 times the static load, which is $225 \mathrm{kN}$. The loading method adopted was that of the single shaft and double wheels running on the steel rail, as shown in Figure 13. 


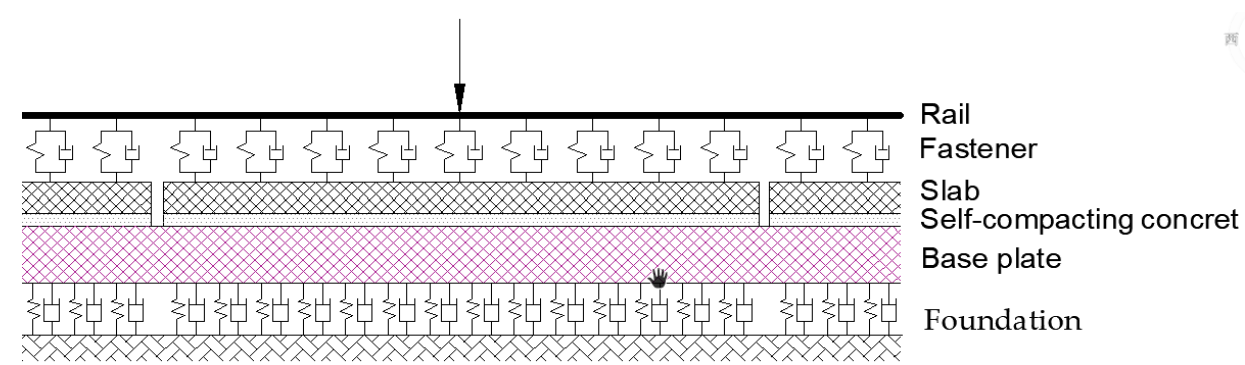

Figure 13. Loading method.

\subsubsection{Force Characteristics of Base Plate}

The deformation of the base plate under the applied load is shown in Figure 14. The deformation of the base plate was largest at the point of load application. A similar deformation response was obtained in the SCC layer. The longitudinal tension of the base plate was greater than the lateral tensile stress, and the maximum longitudinal tension stress appeared on the lower surface of the base plate directly below the load point, as shown in Figure 15a,b, while the maximum lateral tension stress appeared at the mid-span part of the lower surface of the base plate as shown in Figure 15c,d.

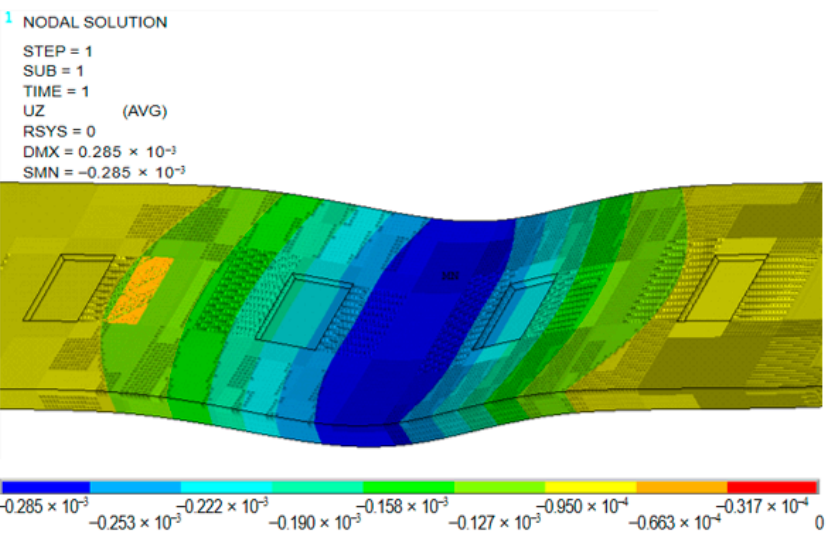

Figure 14. Deformation of the base plate.

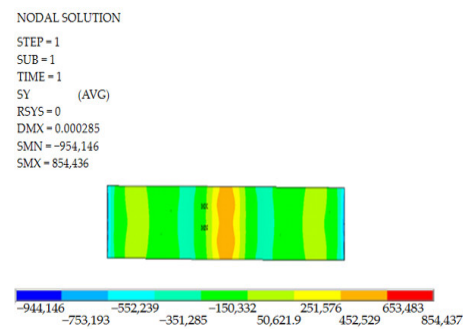

(a)

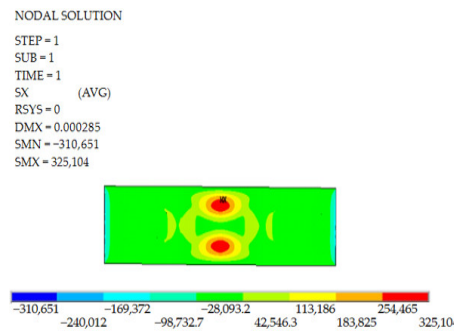

(c)

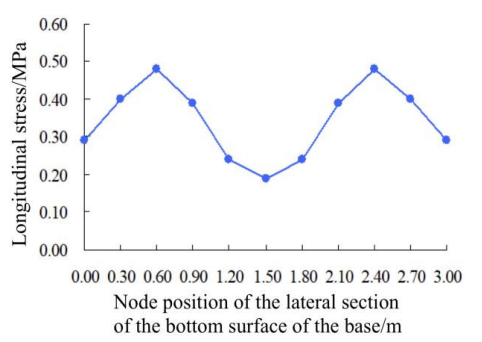

(b)

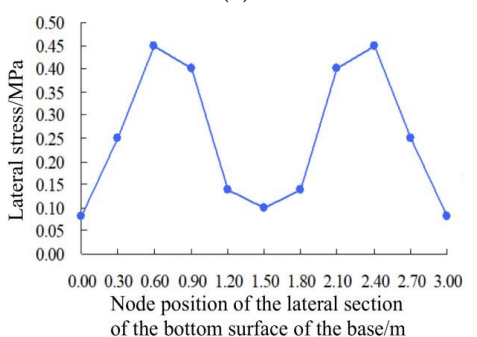

(d)

Figure 15. Stress diagram of the mid-span cross section of the bottom surface of the base plate. (a) Longitudinal stress cloud diagram; (b) longitudinal stress data graph; (c) lateral stress cloud diagram; (d) lateral stress data graph. 


\subsubsection{Damage and Cracking of the Base Plate}

The maximum tension of the base, which is also the longitudinal tension stress, had a maximum value at the bottom of the base plate directly below the load application point. That is, at the mid-span position. Figure 16a shows the curve of longitudinal tensile stress of the cross-section node of the base due to the number of loads.

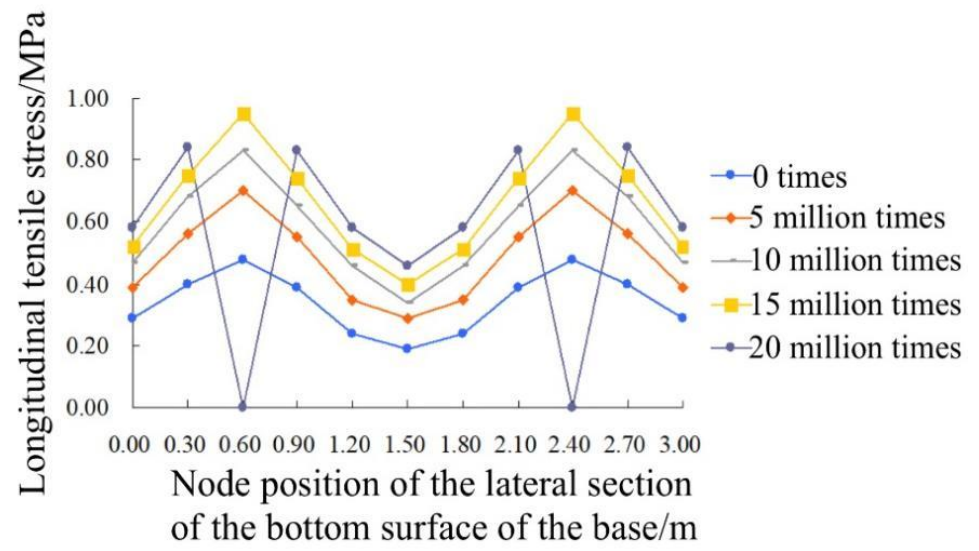

(a)

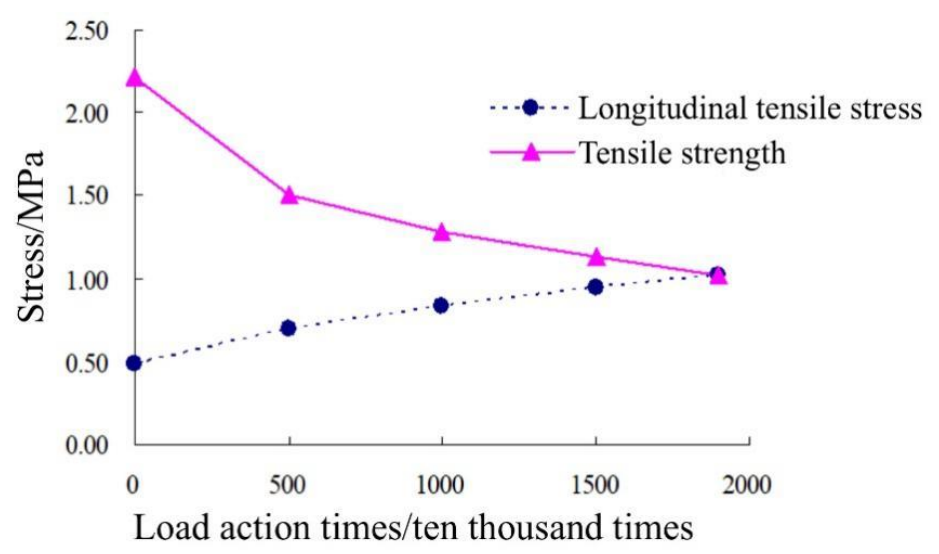

$(\mathbf{b})$

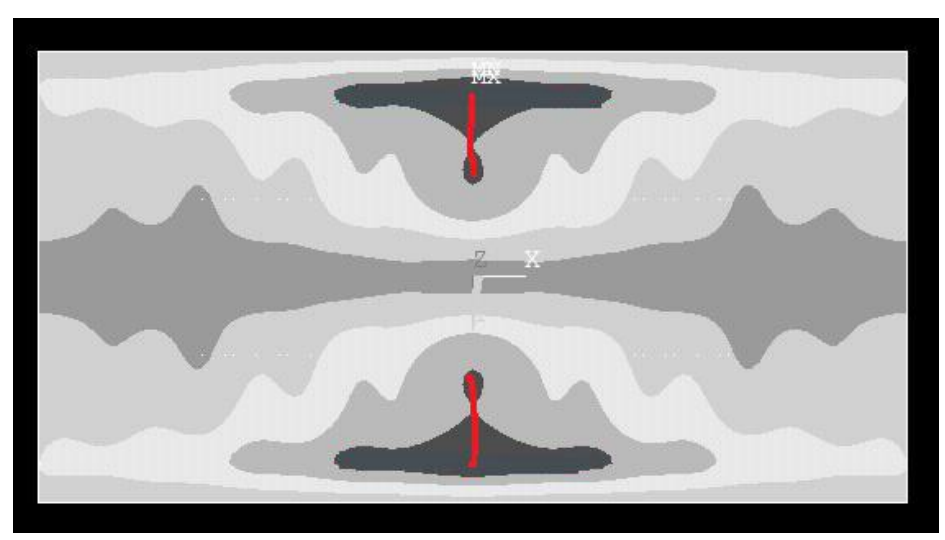

(c)

Figure 16. Damage and cracking behavior of SCC. (a) Longitudinal tension stress of the mid-span lateral section of the bottom surface of the base plate; (b) cracking time at the mid-span part of the bottom surface of the base plate; (c) location of cracks in the bottom layer of the base plate. 
As is shown in Figure 16a, with the increasing number of load actions, the stress of the structural layer gradually increased. Before the application of 5 million times loads, the longitudinal tension stress of the base changed significantly. On average, the stress increased by $0.044 \mathrm{MPa}$ for every 1 million applications of the fatigue load. However, the longitudinal stress of the base increased slowly when the load action was between 5 and 15 million times. At this stage, the stress increased by $0.025 \mathrm{MPa}$ for every 1 million actions. Under fatigue force, the base concrete became gradually damaged, and the residual strength gradually decreased. When applying load 19 million times, the longitudinal tension stress of concrete at the middle span of the bottom of base reached its tensile strength (Figure 16b). Thus, cracks were observed, since the stress degraded to zero at this point. With further accumulation of loads, the cracks of the base propagated from the edge of the plate to the plate (Figure 16c).

\subsection{Parametric Analysis}

\subsubsection{Influence of the Position of the Load}

The CRTSIII BT system is expected to show varying properties at different loading points. To ascertain this, three typical working conditions were considered in this section. Working condition 1-loaded on the sleeper in the middle of slab span; working condition 2-loaded on the sleeper at a quarter of the slab; working condition 3-loaded on the sleeper at the end of the slab, as shown in Figure 17.

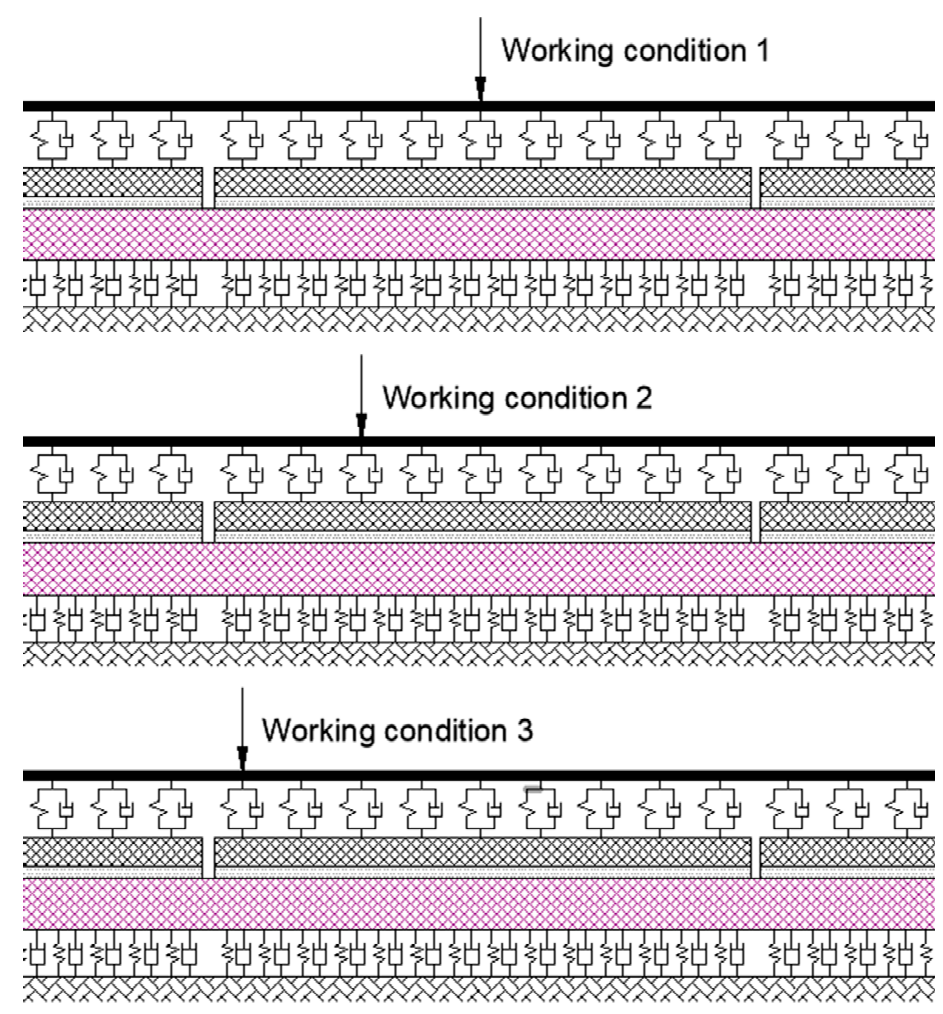

Figure 17. Three typical working conditions.

(1) Working condition 1-loaded on the sleeper in the middle of slab span

For working condition, 1-loaded on the sleeper in the middle of slab span; the stress cloud diagram of the base with fatigue load up to 15 million times is shown in Figure 18. The stress of the base plate under the maximum different fatigue times is shown in Table 4 . 


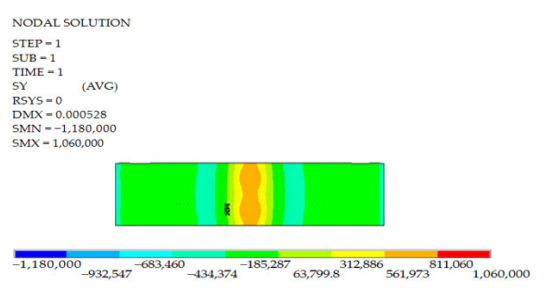

(a)

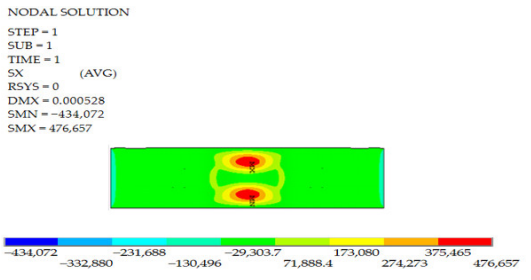

(b)

Figure 18. Stress distribution diagram of the base plate under 16 million applications of fatigue load (working condition 1). (a) Longitudinal stress of base plate; (b) lateral stress of base plate.

Table 4. Maximum stress of the base under working condition 1.

\begin{tabular}{cccc}
\hline & 1 Time & 5 Million Times & 15 Million Times \\
\hline Longitudinal tensile stress $(\mathrm{MPa})$ & 0.48 & 0.70 & 0.95 \\
Lateral tensile stress $(\mathrm{MPa})$ & 0.45 & 0.67 & 0.91 \\
\hline
\end{tabular}

Based on the conclusions deduced from Section 3.1, for working condition 1, the maximum lateral tension stress at the midspan of the base plate is located at the edge of the lower surface of the base plate.

The development of the maximum lateral stress on the lower surface of the base plate at the mid-span position under fatigue load is shown in Figure 19a. With action of the fatigue load, the stress on the section continued to increase. However, at a fatigue load of about 20 million times, the stress on the edge of the base plate suddenly changed to zero; that is, the base plate concrete cracked at this position (Figure 19b).

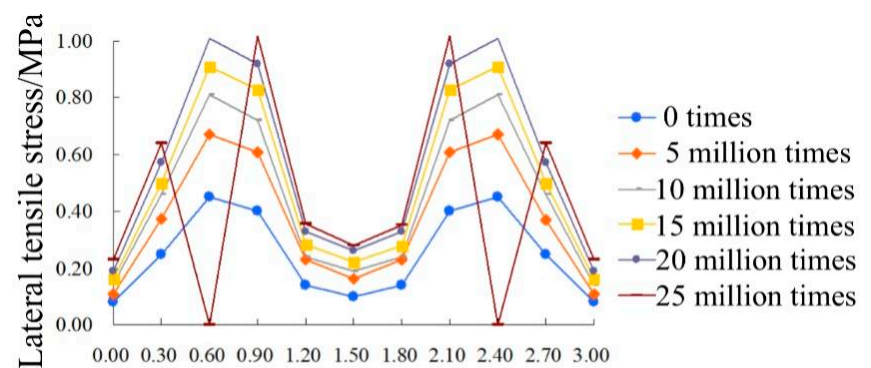

Node position of the lateral section

of the bottom surface of the base $/ \mathrm{m}$

(a)

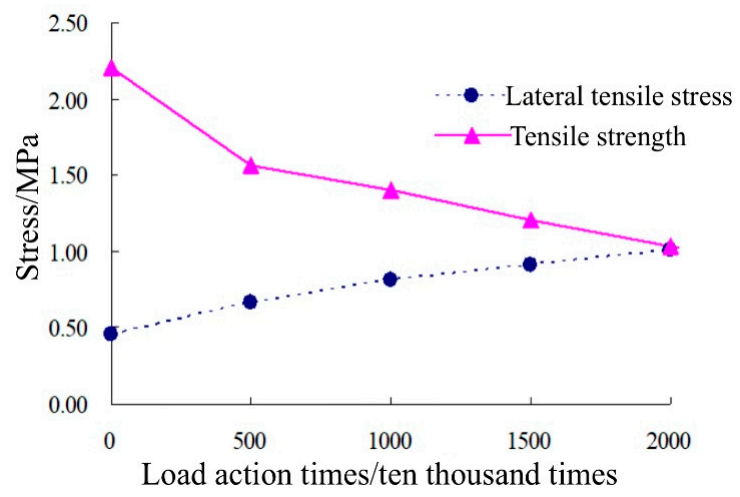

(b)

Figure 19. Lateral mechanical characteristics of base plate under fatigue load (working condition 1). (a) Maximum stress development diagram of the bottom surface at the mid-span position; (b) number of cracks at the maximum tension stress. 
(2) Working condition 2-load acted on the top of the sleeper at a quarter of the slab

For working condition 2-loaded on the top of the sleeper at a quarter of the slab. The stress distribution diagram of the base plate when the fatigue is loaded up to 15 million times is shown in Figure 20, and the maximum stress is shown in Table 5.

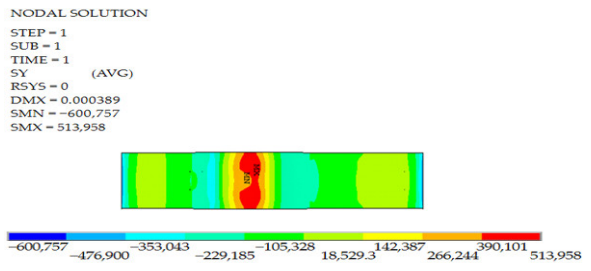

(a)

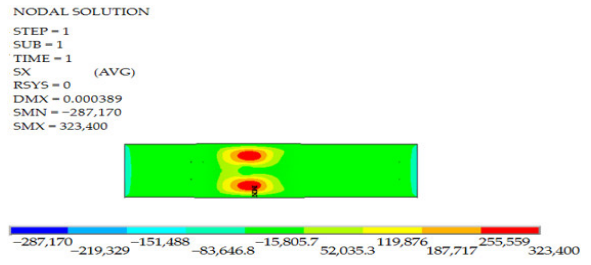

(b)

Figure 20. Stress distribution diagram of the base plate under 15 million applications of fatigue load (working condition 2). (a) Longitudinal stress of base plate; (b) lateral stress of base plate.

Table 5. Maximum stress of the base under working condition 2.

\begin{tabular}{cccc}
\hline & $\begin{array}{c}\text { 1 Time of Fatigue } \\
\text { Load }\end{array}$ & $\begin{array}{c}\mathbf{5} \text { Million Times of } \\
\text { Fatigue Load }\end{array}$ & $\begin{array}{c}\text { 15 Million Times of } \\
\text { Fatigue Load }\end{array}$ \\
\hline $\begin{array}{c}\text { Longitudinal tensile } \\
\text { stress }(\mathrm{MPa})\end{array}$ & 0.45 & 0.61 & 0.95 \\
$\begin{array}{c}\text { Lateral tensile stress } \\
(\mathrm{MPa})\end{array}$ & 0.46 & 0.59 & 0.86 \\
\hline
\end{tabular}

As shown in Figure 20, for working condition 2, the maximum longitudinal tension stress of the base plate was located on the lower surface of the base plate below the sleeper at a quarter span.

Figure 21a shows the development of the maximum longitudinal tensile stress of the base concrete under the fatigue load of this section. The tensile stress near the bottom of the sleeper was relatively large, and with the increase in fatigue load, the stress on the section continued to increase. When a fatigue load was applied 3 million to 12 million times the longitudinal tensile stress increased rapidly, with maximum longitudinal tensile stress increasing by $0.037 \mathrm{MPa}$ for every 1 million applications of fatigue load. When the load accumulated to 16 million times, the tension near the bottom of the sleeper suddenly changed to zero, indicating that cracking occurred at this time (Figure 21b).

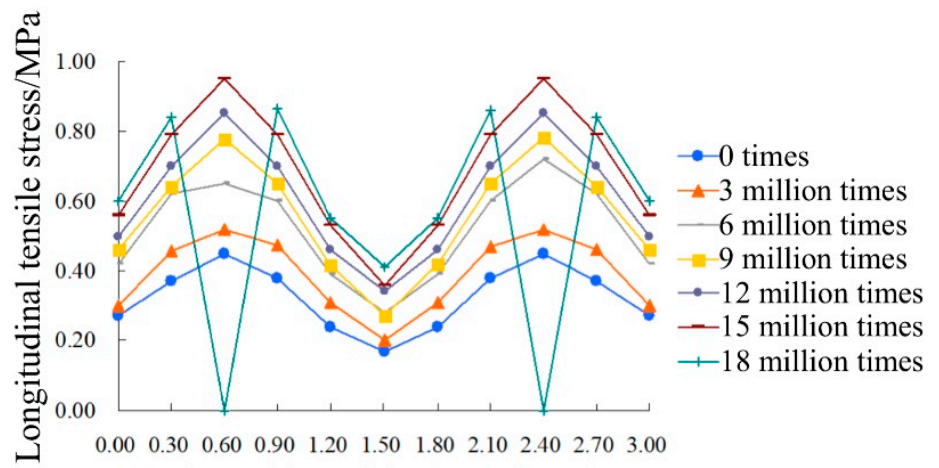

Node position of the lateral section of the bottom surface of the base $/ \mathrm{m}$

(a)

Figure 21. Cont. 


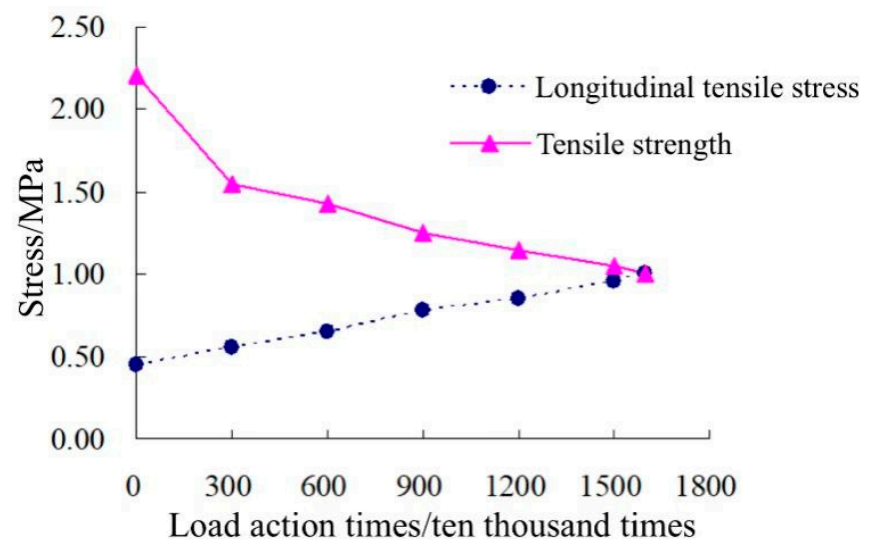

(b)

Figure 21. Longitudinal mechanical characteristics of base plate under fatigue load (working condition 2). (a) Cross-sectional stress development diagram at the maximum longitudinal tensile stress of the base plate; (b) number of cracks at the maximum longitudinal tensile stress of the base plate.

(3) Working condition 3: load acted on the top of the sleeper at the end of the slab

For working condition 3, the load was applied to the top of the sleeper at the end of the slab. The stress distribution diagram of the SCC layer fatigue load applied 12 million times is shown in Figure 22. The stress maximum stress distribution diagram of the base plate under a fatigue load of 12 million applications (working condition 3), is shown in Table 6.

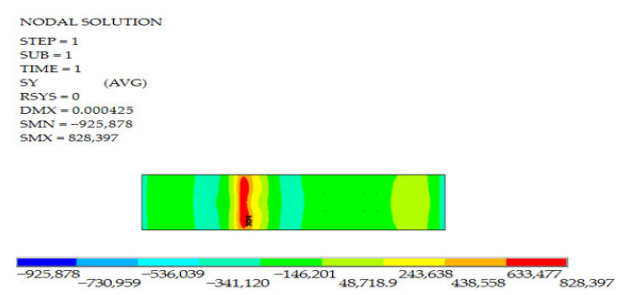

(a)

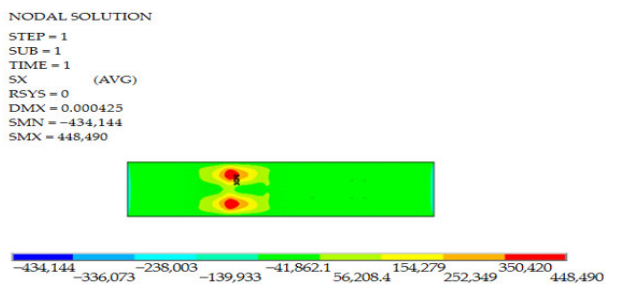

(b)

Figure 22. Stress distribution diagram of the base plate under fatigue load of 12 million applications (working condition 3). (a) Longitudinal stress of base plate; (b) lateral stress of base plate.

Table 6. Maximum stress of the base under working condition 3.

\begin{tabular}{cccc}
\hline & $\begin{array}{c}\text { 1 Time of Fatigue } \\
\text { Load }\end{array}$ & $\begin{array}{c}\text { 6 Million Times of } \\
\text { Fatigue Load }\end{array}$ & $\begin{array}{c}\text { 12 Million Times of } \\
\text { Fatigue Load }\end{array}$ \\
\hline $\begin{array}{c}\text { Longitudinal tensile } \\
\text { stress }(\mathrm{MPa})\end{array}$ & 0.76 & 0.92 & 1.12 \\
$\begin{array}{c}\text { Lateral tensile stress } \\
(\mathrm{MPa})\end{array}$ & 0.54 & 0.82 & 1.05 \\
\hline
\end{tabular}

It can be seen in Figure 22 that for working condition 3, the maximum longitudinal tensile stress of the base plate was located at the slab end sleeper on the lower surface of the base. Under the action of fatigue load, the development of the maximum longitudinal tensile stress of the base plate is shown in Figure 23a. With continued action of the fatigue load, the stress on the section continued to grow. When the fatigue load applied reached 13 million times, the maximum longitudinal tensile stress of the base concrete under the sleeper suddenly changed to zero, indicating that cracking occurred at this time (Figure 23b). 


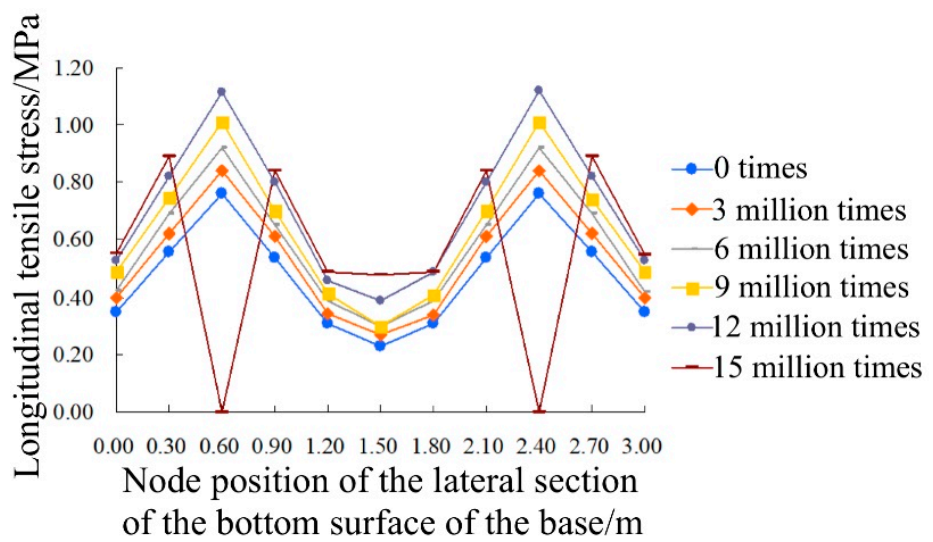

(a)

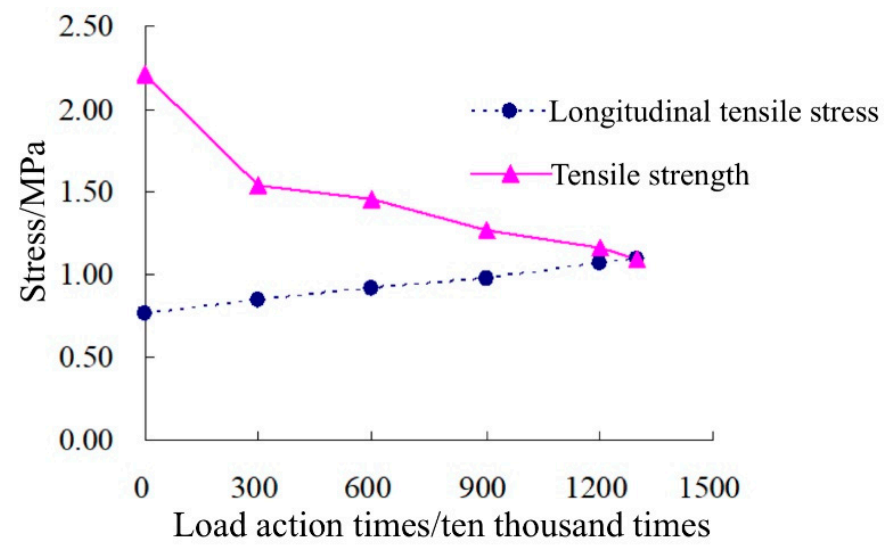

(b)

Figure 23. Longitudinal mechanical characteristics of base plate under fatigue load (working condition 3). (a) Cross-sectional stress development diagram at the maximum longitudinal tensile stress of the base plate; (b) number of cracks at the maximum longitudinal tensile stress of the base plate.

\section{(4) Comparative analysis}

By comparing the three working conditions, it can be deduced that when the CRTSIII BT structure system is in working condition 3, the stress of the base plate is relatively large. Under the three working conditions, the lateral and longitudinal tensile stresses of the base concrete increase with the increase of the number of loads. Among them, under working condition 2, the longitudinal tensile stress increased the fastest when an average of 1 million load applications, resulted in stress increase by $0.033 \mathrm{MPa}$. Under working condition 3 , the lateral stress increased the fastest, where an average of 1 million load actions resulted in stress increase by $0.043 \mathrm{MPa}$. For the tension of the base under the three working conditions, the longitudinal value was always larger than the lateral one, and this played a major part in fatigue damage evolution. In structural design, attention should be paid to the calculation of longitudinal stress.

Comparing the longitudinal and lateral tensile stress of the base, it can be seen that when the load was applied to the slab-end sleeper, the longitudinal and lateral stresses of the base were increased the most. That is to say, compared with working condition 1 , the maximum longitudinal and lateral tensile stresses of the base increased by $58.3 \%$ and $20.0 \%$, respectively, while the maximum longitudinal and lateral tensile stress of the base increased by $68.9 \%$ and $17.4 \%$, respectively compared to condition 2 . Therefore, the base at the end of the slab is the weakness zone. For the overall design of the CRTSIII SBT, strengthening the design of the structural layer at the end of the slab is necessary. 
Table 7 shows the cracking time of the base plate under different working conditions. The base concrete, cracking time of working condition 3 was the earliest to occur, which was $31.6 \%$ and $18.8 \%$ earlier than that of working conditions 1 and 2 , respectively. This implies that when the train passes through the track structure, the farther to the slab end, the more unfavorable the force on the structure.

Table 7. The earliest cracking loading time of base plate under different working conditions.

\begin{tabular}{lccc}
\hline & $\begin{array}{c}\text { Working } \\
\text { Condition 1 }\end{array}$ & $\begin{array}{c}\text { Working } \\
\text { Condition 2 }\end{array}$ & $\begin{array}{c}\text { Working } \\
\text { Condition 3 }\end{array}$ \\
\hline Base plate (ten thousand times) & 1900 & 1600 & 1300 \\
\hline
\end{tabular}

\subsubsection{Fatigue Damage Evolution under Varying Axle Loads}

To obtain the mechanical behavior and fatigue evolution of CRTSIII SBT with various axle loads, the structure's adaptability to axle loading was studied. According to developing tendency of heavy load trains and heavy haul railways, the axle loads were taken as 25, 27, $30,32.5,35,37.5$ and $40 \mathrm{t}$ respectively. The action mode of train load is that single axle and double wheels act in the slab middle.

(1) Mechanical characteristics of CRTSIII SBT structure under different axle loads

For different axle loads, the base generated a maximum stress value on its bottom just below the loading point. Due to many working conditions, only the cloud picture of longitudinal tensile stress of base when the axle load is $25 \mathrm{t}$ is shown (Figure 24). At the same time, the maximum tension on the longitudinal direction of the base subjected to varying axle loads is indicated in Table 8 . It can be observed from the Table that the stress on the base gradually increased with the increase in axle loads.

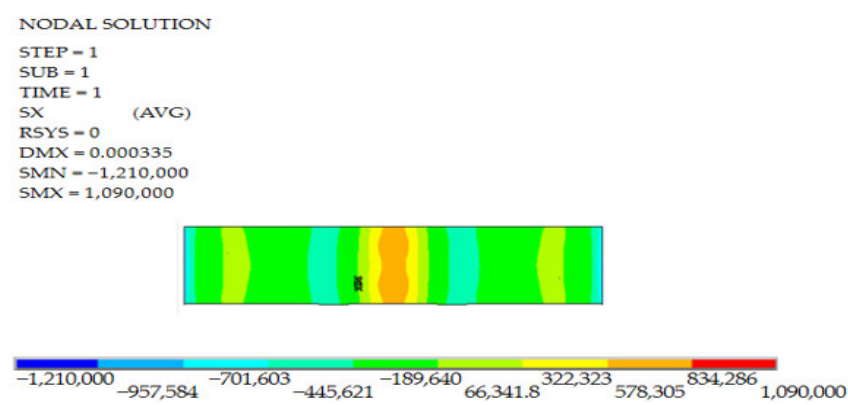

Figure 24. Diagram of calculation of longitudinal tensile stress of base (25 $t)$.

Table 8. Maximum Longitudinal Tensile Stress.

\begin{tabular}{cccccccc}
\hline Axle Load $(\mathrm{t})$ & 25 & 27 & 30 & 32.5 & 35 & 37.5 & 40 \\
\hline Base $(\mathrm{MPa})$ & 0.40 & 0.43 & 0.48 & 0.53 & 0.57 & 0.61 & 0.63 \\
\hline
\end{tabular}

\section{(2) Comparative analysis}

The variations of the greatest tension on the longitudinal direction of the base applied varying axle loads with loading times are shown in Figure 25.

The structure layer stress varied with different axle loading. The stress of base concrete increased with the axle load, and the maximum longitudinal tensile stress increased with the action times. 


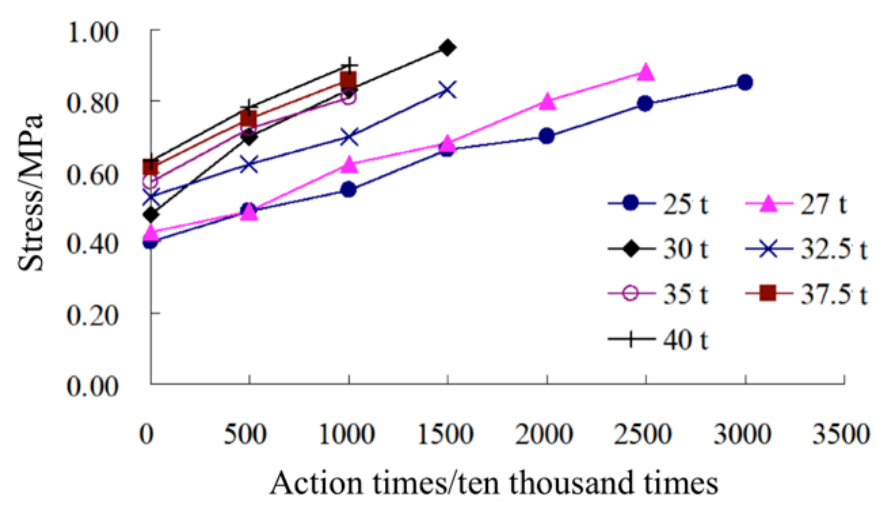

Figure 25. The variation of the maximum longitudinal tension of the base changing with loading times.

During the fatigue process of CRTSIII SBT, tension stress changes were observed strictly. The tensile stress was usually high longitudinally, which plays an important part in the fatigue evolution. Crack numbers of the base subjected to different axle loads are summarized in Table 9. With the increase of axle load, the stress of each structural layer increased, and the damage rate of concrete also increased, resulting in earlier cracks in concrete. An increase in axle load to about $35 \mathrm{t}$, resulted in an obvious the damage of the base. The results illustrate that to use CRTSIII SBT in heavy load railways with greater axle loads, and to improve durability and service performance, attention should be paid to structural design and detailing to strengthened slabs and diminish concrete stress.

Table 9. The earliest time of cracking.

\begin{tabular}{cccccccc}
\hline Axle Load $(\mathbf{t})$ & $\mathbf{2 5}$ & $\mathbf{2 7}$ & $\mathbf{3 0}$ & $\mathbf{3 2 . 5}$ & $\mathbf{3 5}$ & $\mathbf{3 7 . 5}$ & $\mathbf{4 0}$ \\
\hline Base $(10,000$ times) & 3500 & 2800 & 1900 & 1700 & 1500 & 1400 & 1200 \\
\hline
\end{tabular}

\section{Discussion}

The results of the study can be summarized as follows.

(1) Acceleration of the base is lower than that of the track slab in the early stages of the train load by half. The isolation layer can effectively reduce the downward transmission of vibration from the upper part of the track structure. However, the increase in the rigidity of the fastener and the isolation layer has an adverse effect on the stress of the structural system, especially the stress on the base.

(2) By comparing the displacement and stress under static load and fatigue load, the errors under the two conditions are acceptable and the variation law of the real value is consistent with that of the calculated value, similar to results in [41]. Therefore, the fatigue-loaded model can effectively describe the mechanical behavior of the base plate of CRTSIII SBT structure under heavy haul train forces.

(3) As the number of fatigue loads increases, the stress of the structural layer gradually increases, the base concrete becomes damaged, and the residual strength gradually decreases. Until the longitudinal tensile stress of the concrete at the mid-span portion at the bottom of the base is equal to its tensile strength, concrete cracks appear, and then the bottom plate cracks, gradually expanding from the edge to the center of the plate.

(4) For the tensile stress of the base under the three working conditions, the longitudinal tension stress is always greater than the lateral stress. Hence, it is critical to attach importance to the simplified analysis of the longitudinal stress in t structural design. When the load acts on the slab-end sleeper, both the longitudinal and lateral stresses of the base reach their maximum, implying the base at the end of slab is the weak 
zone. Thus, for the overall design of CRTSIII SBT, it is necessary to strengthen the design of the structural layer at the end of the slab.

\title{
5. Conclusions
}

The following conclusion can be made.

(1) For the base, the greater the thickness of self-compacting layer, the more time it takes for cracks to appear. Appropriately increasing the self-compacting thickness can effectively delay the time it takes for cracks to appear in the structural layer.

(2) With increase of axle load, the stress of each structural layer increases, and the damage rate of concrete also increases, resulting in earlier cracks in concrete. An axle load in excess of $35 \mathrm{t}$ has a greater impact on damage of the base.

(3) When CRTSIII SBT is applied in a heavy-haul railway with greater axle load, the thickness of the SCC layer could be appropriately increased to reduce fatigue damage and cracks of the base plate. The concrete level at the end of slab should be strengthened, and the rebar number increased.

\begin{abstract}
Author Contributions: Conceptualization, Z.Z.; methodology, J.H.; software, J.H. and X.H.; validation, X.H. (Xudong Huang), W.W. and Z.H.; formal analysis, J.H.; investigation, A.A.S.; resources, Y.Y. and Z.X.; data curation, X.H. (Xianfeng He); writing - original draft preparation, J.H.; writingreview and editing, X.H. (Xianfeng He); visualization, X.H. (Xudong Huang); supervision, Z.H.; project administration, W.W.; funding acquisition, Z.Z. All authors have read and agreed to the published version of the manuscript.

Funding: This research was funded by [ the Scientific Research Test Project of China Railway Corporation] grant number [Grant SY2016G001], [Natural Science Foundation of Hunan Province, China] grant number [Grant 2019JJ40384], [High-Speed Railway Foundation Joint Fund Project] grant number [Grant U1734208].
\end{abstract}

Institutional Review Board Statement: Not applicable.

Informed Consent Statement: Not applicable.

Data Availability Statement: Not applicable.

Conflicts of Interest: The authors declare no conflict of interest.

\section{References}

1. Derkowski, W.; Slaga, L. The Effect of Too Stiff Rail to Base Fastening on Damage Mechanism In RC Ballastless Track Structure. Technol. News Focus 2020, 21, 1544-1556. [CrossRef]

2. Libor, I.; Janka, S.; Michal, S. The railway superstructure monitoring in Bratislava tunnel no. 1-Section of ballastless track and its transition areas. MATEC Web Conf. 2017, 117, 00063.

3. Weiqi, Z.; Xingwang, S.; Zhihui, Z.; Tao, S. Effect of reverse bending deformation of large-span cable-stayed bridge on ballastless tracks' behaviors. Struct. Eng. Mech. 2021, 80, 169-179.

4. Weiqi, Z.; Xingwang, S.; Hongqiang, H.; Hongyi, X.; Ying, Y. Use of Rubber Mat to Improve Deformation Behaviors of Ballastless Tracks Laid on Bridges. Adv. Civ. Eng. 2020, 2020, 8821402.

5. Zhiping, Z.; Mengxuan, Y.; Fushan, L.; Ahmed, S.A.; Weidong, W.; Xiaobai, M. Dynamic response of CRTS I double-block ballastless track under three-dimensional temperature and falling-shaft impact loadings. Adv. Mech. Eng. 2021, 13, 16878140211004317.

6. Wenner, M.; Marx, S.; Koca, M. Additional rail stresses due to long-term deformations of railway viaducts with ballastless track-model and reality. Bautechnik 2019, 96, 674-695. [CrossRef]

7. Yang, Y.; Jun, Z.G.; Gang, W.; Cao, D.-F. Finite element analysis of ballastless track slabs reinforced with fiber-reinforced polymer bars. Adv. Struct. Eng. 2021, 24, 3405-3419. [CrossRef]

8. Hsu, W.-K.; Shih, N.-H.; Lee, Y.-L.; Lebon, F.; Rizzoni, R.; Gupta, M. Railway Continuous Prestressed Concrete Bridge Design in Ballastless Track Turnout Zones. Technologies 2017, 5, 11. [CrossRef]

9. Zhaowei, C.; Hui, F. Influence of pier settlement on contact behavior between CRTS II track and bridge in high-speed railways. Eng. Struct. 2021, 235, 112007.

10. Ramos, A.; Correia, A.G.; Calcada, R.; Costa, P.A. Stress and permanent deformation amplification factors in subgrade induced by dynamic mechanisms in track structures. Int. J. Rail Transp. 2021, 9, 1-33. [CrossRef]

11. Robertson, I.; Masson, C.; Sedran, T.; Barresi, F.; Caillau, J.; Keseljevic, C.; Vanzenberg, J.M. Advantages of a new ballastless trackform. Constr. Build. Mater. 2015, 92, 16-22. [CrossRef] 
12. Yu, Z.; Xie, Y.; Shan, Z.; Li, X. Fatigue Performance of CRTS III Slab Ballastless Track Structure under High-speed Train Load Based on Concrete Fatigue Damage Constitutive Law. J. Adv. Concr. Technol. 2018, 16, 233-249. [CrossRef]

13. Jiang, W.; Xie, Y.; Wu, J.; Long, G. Influence of age on the detection of defects at the bonding interface in the CRTSIII slab ballastless track structure via the impact-echo method. Constr. Build. Mater. 2020, 265, 120787. [CrossRef]

14. Yu, Z.; Xie, Y.; Tian, X.; Rizos, D. Research on Mechanical Performance of CRTSIII slab-Type Ballastless Track Structure under Temperature Load Based on Probability Statistics. Adv. Civ. Eng. 2019, 2019, 2975274.

15. Xu, L. Research on Optimized Construction Technology of CRTSIII Slab Ballastless Track Base Plate. Sci. Technol. Innov. Inf. 2020, 24, 132-136.

16. Zuoxin, D. Summary of Base Plate Construction Technology in Plate Uncovering Test of CRTSIII Ballastless Tracks. Build. Constr. 2018, 40, 1912-1932.

17. Hongwei, R. Construction Technology of Base Plate of CRTSIII Type Slab Ballastless Track. Railw. Constr. Technol. 2015, 32, 85-87.

18. Zeng, Z.-P.; Wang, J.-D.; Shen, S.-W.; Ping, L.; Shuaibu, A.A.; Wang, W.-D. Experimental study on evolution of mechanical properties of CRTSIII ballastless slab track under fatigue load. Constr. Build. Mater. 2019, 210, 639-649.

19. Zhu, S.; Wang, M.; Zhai, W.; Cai, C.; Zhao, C.; Zeng, D.; Zhang, J. Mechanical property and damage evolution of concrete interface of ballastless track in high-speed railway: Experiment and simulation. Constr. Build. Mater. 2018, 187, 460-473. [CrossRef]

20. Yuan, J.; Chen, X.; Shen, N.; Fan, X.; Lu, J. Experimental study on the pore structure variation of self-compacting rubberised concrete under fatigue load. Road Mater. Pavement Des. 2021, 22, 716-733. [CrossRef]

21. Huang, M.-S.; Gül, M.; Zhu, H.-P. Vibration-based structural Damage Identification under Varying Temperature Effects. J. Aerosp. Eng. 2018, 31, 04018014. [CrossRef]

22. Huang, M.; Lei, Y.; Li, X. Structural Damage Identification Based on l(1)Regularization and Bare Bones Particle Swarm Optimization with Double Jump Strategy. Math. Probl. Eng. 2019, 2019, 5954104. [CrossRef]

23. Huang, M.; Zhao, W.; Gu, J.; Lei, Y. Damage Identification of a Steel Frame Based on Integration of Time Series and Neural Network under Varying Temperatures. Adv. Civ. Eng. 2020, 2020, 4284381. [CrossRef]

24. Chen, C.; Yu, L. A hybrid ant lion optimizer with improved Nelder-Mead algorithm for structural damage detection by improving weighted trace lasso regularization. Adv. Struct. Eng. 2020, 23, 468-484. [CrossRef]

25. Chen, C.; Pan, C.; Chen, Z.; Yu, L. Structural damage detection via combining weighted strategy with trace Lasso. Adv. Struct. Eng. 2019, 22, 597-612. [CrossRef]

26. Wang, Z.; Huang, M.; Gu, J. Temperature Effects on Vibration-Based Damage Detection of a Reinforced Concrete Slab. Appl. Sci. 2020, 10, 2869. [CrossRef]

27. Pan, C.-D.; Yu, L.; Liu, H.-L. Identification of moving vehicle forces on bridge structures via moving average Tikhonov regularization. Smart Mater. Struct. 2016, 26, 085041. [CrossRef]

28. Chen, Z.; Pan, C.; Yu, L. Structural damage detection via adaptive dictionary learning and sparse representation of measured acceleration responses. Measurement 2018, 128, 377-387. [CrossRef]

29. Susmel, L. A unifying methodology to design un-notched plain and short-fibre/particle reinforced concretes against fatigue. Int. J. Fatigue 2014, 61, 226-243. [CrossRef]

30. Krüger, H.; Rolfes, R. A physically based fatigue damage model for fibre-reinforced plastics under plane loading. Int. J. Fatigue 2015, 70, 241-251. [CrossRef]

31. Tarifa, M.; Zhang, X.X.; Ruiz, G.; Poveda, E. Full-scale fatigue tests of precast reinforced concrete slabs for railway tracks. Eng. Struct. 2015, 100, 610-621. [CrossRef]

32. Takahashi, T.; Sekine, E. Evaluation of factors contribution to deterioration of track-slab in cold areas. Q. Rep. RTRI 2011, 52, 149-155. [CrossRef]

33. Chapeleau, X.; Sedran, T.; Cottineau, L.M.; Cailliau, J.; Taillade, F.; Gueguen, I.; Henault, J.M. Study of ballastless track structure monitoring by distributed optical fiber sensors on a real-scale mockup in laboratory. Eng. Struct. 2013, 56, 1751-1757. [CrossRef]

34. Pingrui, Z.; Jianhua, Y.; Kejiang, W.; Dong, W.; Wei, L.; Jiawei, W. Model Experiment Study of Continuous Track Slab Tension Cracks. J. Southwest Jiaotong Univ. 2014, 49, 793-798.

35. Lin, H. Research on Static and Dynamic Characteristics of Ballastless Track Based on Fracture and Damage Mechanics; Southwest Jiaotong University: Chengdu, China, 2009.

36. Zhiping, Z.; Guanghui, H.; Xiangdong, H.; Weidong, W.; Senan, Q.A.A.; Ahmed, S.A.; Jundong, W. Statics performance of heavy-haul railway low-vibration track (LVT) under varying loading condition with the finite element method. Sci. Prog. 2021, 104, 00368504211036330 .

37. Lu, S.; Yufen, D.; Peipei, G. Comparison of structural analysis models for slab ballastless track in high-speed railway. J. Southeast Univ. Nat. Sci. Ed. 2013, 43, 938-943.

38. Xu, Q.; Sun, H.; Wang, L.; Xu, L.; Chen, W.; Lou, P. Influence of Vehicle Number on the Dynamic Characteristics of High-Speed Train-CRTS III Slab Track-Subgrade Coupled System. Materials 2021, 14, 3662. [CrossRef]

39. Ma, K.; Li, S.; Long, G.; Xie, Y.; Yu, L.; Xie, Q. Performance Evolution and Damage Constitutive Model of Thin Layer SCC under the Coupling Effect of Freeze-Thaw Cycles and Load. J. Mater. Civ. Eng. 2020, 32, 04020147. [CrossRef]

40. González-Nicieza, C.; Álvarez-Fernández, M.I.; Menéndez-Díaz, A.; Álvarez-Vigil, A.E.; Ariznavarreta-Fernández, F. Failure analysis of concrete sleepers in heavy haul railway tracks. Eng. Fail. Anal. 2008, 15, 90-117. [CrossRef] 
41. Zeng, Z.-P.; Huang, X.-D.; Bin, Y.; Wang, W.-D.; Abdulmumin, A.S.; He, X.-F. Research on the fatigue performance of selfcompacting concrete structure in CRTSIII slab ballastless track under the action of heavy haul train. Constr. Build. Mater. 2021, 303, 124465. [CrossRef]

42. Zhu, K.T.; Zeng, Z.P.; Wu, B.; Wei, W. Mechanical Property Verification of CRTS Ill Slab Track under Train Load. In Proceedings of the 6th International Conference on Electronic, Mechanical, Information and Management Society (EMIM), Shenyang, China, 1-3 April 2016; ACSR-Advances in Computer Science Research. pp. 1464-1469.

43. B 10625-2017; Code for Design of Heavy Haul Railway[S]. National Railway Administration: Beijing, China, 2017.

44. GB 50010-2010; Code for Design of Concrete Structures[S]. China Building Industry Press: Beijing, China, 2015. 